\title{
La lipolyse dans le lait : les différents types, mécanismes, facteurs de variation, signification pratique*
}

\author{
par \\ Y. CHILLIARD ${ }^{* *}$ et G. LAMBERET ${ }^{* * *}$
}

I. INTRODUCTION.

PLAN

II. IMPORTANCE ACTUELLE DE LA LIPOLYSE.

III. DEFINITIONS.

IV. LES ELEMENTS DU SYSTEME LIPOLYTIQUE :

A. Le substrat: les globules gras.

B. Les enzymes :

1. La Lipase Naturelle.

2. LES Lipases LeUCOCytaIRES.

3. LES LIPASES MICROBIENNES.

4. Les aUtres enzymes.

V. MECANISMES D'ACTION DES LIPASES DANS LE LAIT.

A. Action de la lipase naturelle dans le lait refroidi :

1. Liaison lipase-globules gras.

2. ACtivité DE LA LipaSe liÉE a LA CRÈME.

B. Effets de différentes inductions thermiques et mécaniques sur la lipolyse :

1. EFFEt global SUR La Lipolyse.

2. ACTION SUR LES GLOBULES GRAS.

3. INFLUENCE SUR L'INTERACTION LIPASE-MATIÈRE GRASSE.

* Texte tiré de la conférence présentée au Colloque INRA-ENSAR-INAPG sur "la composition chimique du lait et ses incidences technologiques" (Rennes, 26-28 septembre 1984).

** Laboratoire de la Lactation, INRA-Theix - 63122 Ceyrat.

*** Laboratoire de Technologie, INRA-INAPG - 78850 Thiverval-Grignon. 
C. Action des phospholipases et des protéases sur la membrane des globules gras et sur la lipolyse.

VI. FACTEURS PRATIOUES DE VARIATION DE LA LIPOLYSE DANS LE LAIT.

A. Facteurs liés à l'animal et aux conditions d'élevage :

1. EsPèce animale.

2. RACE.

3. Stade de lactation et niveau de production.

4. alimentation.

5. Etat sanitaire.

B. Facteurs liés au matériel de traite.

C. Facteurs liés au stockage, à la collecte et à la transformation.

VII. LIPASES DU LAIT ET QUALITE DES PRODUITS LAITIERS.

VIII. CONCLUSION.

\section{Rés u mé}

Cette revue bibliographique traite de l'importance actuelle de la lipolyse du lait; des mécanismes de la lipolyse spontanée, induite et microbienne; des facteurs pratiques de variation de la lipolyse et de son influence sur la qualité des produits laitiers; et des principales mesures préventives et de contrôle que l'on peut envisager.

\section{S u m m a ry}

MILK LIPOLYSIS: VARIOUS TYPES, MECHANISMS, FACTORS OF VARIATION, PRACTICAL SIGNIFICANCE

This review deals with practical importance of milk lipolysis today; with mechanisms of spontaneous, induced and microbial lipolysis; with practical variation factors of lipolysis and its effect on the quality of dairy products; and with recommandations for prevention and control.

\section{INTRODUCTION}

Le stokage du lait au froid, à la ferme puis à l'usine, est une des mesures qui a permis de simplifier l'organisation matérielle des opérations de collecte et de transformation, si bien que des quantités croissantes de lait ne sont pasteurisées ou traitées que 2, 3 et parfois plus de 4 jours après la traite. Ce stockage au froid n'est pas sans inconvénients, car la matière première subit alors une série de modifications qui peuvent affecter les rendements à la transformation ou la qualité des produits : modifications de la phase colloïdale (caséines, ...) et de la phase grasse, développements bactériens, dégradation des protéines (protéolyse) ou des matières grasses (lipolyse). 
La matière grasse du lait fraîchement sécrété est constituée pour $98 \%$ de triglycérides et pour moins de $0,5 \%$ d'acides gras libres. L'hydrolyse enzymatique des triglycérides par les lipases se traduit par l'augmentation de la teneur en acides gras libres (AGL) du lait. Or, les AGL, et particulièrement ceux qui ont entre 4 et 12 atomes de carbone, entraînent l'apparition de mauvais goûts (de rance, de savon,...) lorsque leur teneur atteint environ $2 \mathrm{mEq} / 100 \mathrm{~g}$ de matières grasses (1) dans le lait, environ $1,5 \mathrm{mEq} / 100 \mathrm{~g} \mathrm{MG}$ dans la crème ou 1,2 à $1,5 \mathrm{mEq} / 100 \mathrm{~g} \mathrm{MG}$ dans le beurre (Kuzdzal-Savoie, 1982a ; Anderson, 1983). Les glycérides partiels (di- et monoglycérides), autres produits de la lipolyse, peuvent aussi donner des mauvais goûts (amertume, ...). En outre, les AGL sont plus sensibles à l'oxydation que les acides gras estérifiés et ils peuvent même la catalyser.

Par ailleurs, la lipolyse entraîne des biais variables dans les différentes méthodes de mesure des taux butyreux et protéiques (Wierre et Grappin, 1979 ; Grappin et Jeunet, 1981), en particulier avec les méthodes où l'on mesure le nombre de liaisons esters en infra-rouge (figure 1).

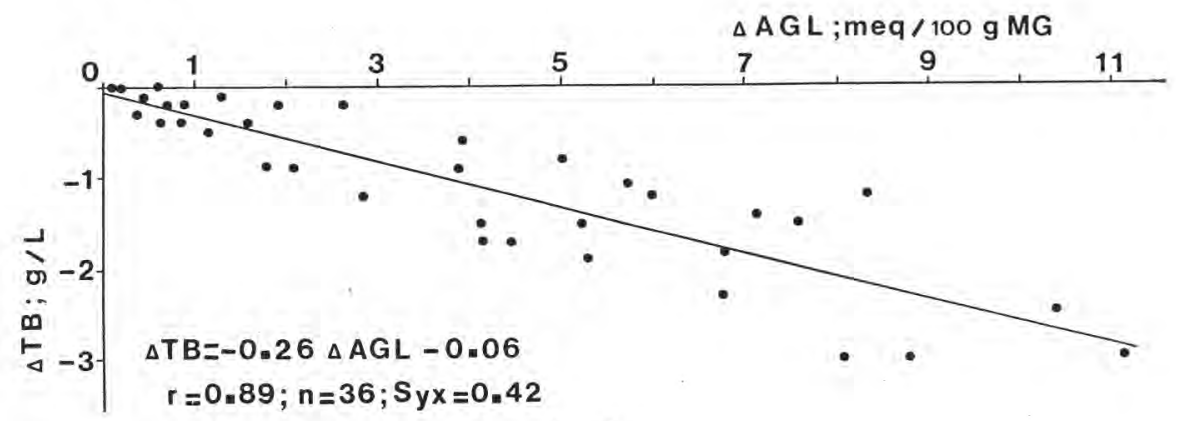

fig. 1

Influence du degré de lipolyse (mesuré par la méthode BDI) sur la variation du taux butyreux du lait mesuré à l'aide d'un appareil infra-rouge (Milko scan ; filtre $A ; 5,7 \mu$ ).

(Y. Chilliard, D. Bauchart et J.M. Trin, non publié).

Effect of lipolysis (as measured by BDI method) on the estimation of milk fat content by infra-red method.

(1) - $1 \mathrm{mEq}$ correspond à 1 mmole d'acides gras libres ou à $0,28 \mathrm{~g}$ d'acidité oléique.

- Teneurs en AGL mesurées par la méthode "BDI " (Bureau of Dairy Industry). Il est important d'indiquer la méthode de dosage employée. Ainsi, la méthode BDI qui ne dose pas tous les acides gras à chaîne courte ou moyenne, sous-estime la valeur réelle d'environ $25 \%$. Par contre, les méthodes par extraction aux solvants surestiment la valeur réelle de 0,7 à $1,5 \mathrm{mEq} / 100 \mathrm{~g} \mathrm{MG}$ (Chilliard et al., 1983).

- Les seuils indiqués sont très approximatifs. Ils varient en particulier avec le $\mathrm{pH}$ du produit et avec la nature des AGL (longueur de chaîne). 
La Fédération Internationale de Laiterie a consacré trois documents volumineux (1974, 1975 et 1980) au problème de la lipolyse, qui synthétisent et développent l'importante somme de travaux de recherche effectués pendant plusieurs décennies aux U.S.A., puis en Océanie et en Europe.

\section{IMPORTANCE ACTUELLE DE LA LIPOLYSE}

L'importance pratique de la lipolyse semble avoir fortement augmenté en France au cours des années 70, mais de façon variable selon les régions; elle représenterait en 1980 une perte financière équivalente à $0,6 \%$ de la collecte ; des entreprises signalent au Comité d'Action Lipolyse de l'Association Laitière Française que jusqu'à $20 \%$ du lait collecté peut être impropre à certaines fabrications. Il est toutefois difficile de généraliser en l'absence de statistiques globales.

Récemment, les normes administratives françaises pour la qualité du beurre ont été abaissées à $1,1 \mathrm{mEq} / 100 \mathrm{~g} \mathrm{MG}$ pour 1'exportation et à $1,25 \mathrm{mEq} / 100 \mathrm{~g} \mathrm{MG}$ pour l'intervention. Une enquête de la Direction des Services Vétérinaires et du Laboratoire d'Hygiène Alimentaire en 1981-82 portant sur 135 usines françaises et 2400 échantillons correspondant à 425000 tonnes de beurre soumis au contrôle des beurres pasteurisés (donc parmi ceux de meilleure qualité) montre que $20 \%$ des échantillons (correspondant à environ $7 \%$ du tonnage) dépassent 1e seuil de 1,25 mEq/100 g MG (Amariglio, 1984). La moitié des beurres français présenterait des teneurs trop élevées en AGL (Laudren, 1983). En 1973-1974, un contrôle des beurres dans 6 pays européens a montré que 4 d'entre eux présentaient des taux anormalement élevés d'AGL dans plus de $20 \%$ des beurres contrôlés (Downey, 1980).

Les réponses de différents comités nationaux à un questionnaire réalisé par la FIL (1982) font apparaître 4 groupes de pays parmi ceux qui ont répondu :

1. Les pays où la lipolyse n'est plus un problème important (U.S.A., Australie, Nouvelle-Zélande, Suède, Danemark, Pays-Bas, Angleterre, Allemagne de l'Ouest, Autriche, Suisse). Dans le cas de la Suisse, la traite est généralement faite en pots trayeurs et il y a peu de stockage à la ferme.

En Australie, on signale toutefois des problèmes liés aux fins de lactation et à la durée de stockage. En outre, l'utilisation des laits lipolysés est défavorable lorsqu'on recherche du moussage (capuccino, milk shakes, ...) en raison des propriétés antimoussantes des produits de la lipolyse (glycérides partiels,...). Aux U.S.A., Shipe et Senyk (1981) signalent aussi que $25 \%$ des laits du commerce auraient encore des goûts «lipolysés».

2. Les pays où la lipolyse est encore, à des degrés divers, un problème important (France, Belgique, Irlande, Finlande, Norvège, Tchécoslovaquie, Afrique du Sud). En Norvège, $50 \%$ des défauts de goût des 
laits de tank seraient dus à la lipolyse. Parmi les problèmes souvent cités, on relève les fins de lactation, la surtraite, les matériels de traite, la température et la durée du stockage du lait cru avant pasteurisation, l'hygiène et surtout les germes psychrotrophes. Des problèmes sont souvent rencontrés avec les crèmes et les beurres (conditions de fabrication, ....).

3. Les pays où la lipolyse n'est pas encore un problème (tels que l'Espagne et probablement des pays n'ayant pas répondu au questionnaire) dans la mesure où les problèmes de qualité bactériologique des laits sont tels qu'ils masquent totalement l'aspect lipolyse.

4. Enfin, le cas du Japon (et probablement d'autres pays) où le consommateur n'est pas sensible aux goûts lipolysés jusqu'à des seuils aussi élevés que $10 \mathrm{mEq} / 100 \mathrm{~g} \mathrm{MG}$ (contre $2 \mathrm{mEq} / 100 \mathrm{~g}$ MG en Europe).

\section{DEFINITIONS}

La teneur en AGL d'un lait représente la somme des AGL initiaux [AGL présents dans le lait fraîchement sécrété (2), généralement compris entre 0,2 et $0,4 \mathrm{mEq} / 100 \mathrm{~g} \mathrm{MG}$ ] et des AGL apparus au cours de la lipolyse pendant une certaine durée de stockage après la traite. On distingue classiquement 3 grands types de lipolyse :

$1^{\circ}$ La lipolyse induite, qui résulte de l'action de la lipase naturelle (sécrétée par la mamelle) sur les globules gras du lait, après que ceux-ci aient été endommagés par des chocs thermiques (refroidissement, réchauffement, ...) et mécaniques (turbulences, moussage, ...). Ces facteurs permettent aux lipases d'avoir un plus large accès aux triglycérides.

$2^{\circ}$ La lipolyse spontanée, qui résulte des variations de la composition et des propriétés du lait natif en relation avec l'état physiologique, nutritionnel, sanitaire, ... des animaux. En fait, le terme « lipolyse spontanée » est abusif dans la mesure où, en dehors de cas particuliers, il n'existe généralement pas de lipolyse dans le lait pendant son séjour dans la mamelle ou lorsqu'il est maintenu à $37^{\circ} \mathrm{C}$ après avoir été prélevé manuellement (Bengtsson et Olivecrona, 1982), du fait que la lipase ne peut que très difficilement agir sur les globules gras natifs. Nous parlerons donc plutôt du facteur animal, c'est-à-dire de l'interaction entre les propriétés du lait natif de chaque individu (quantité de lipase, propriétés des globules gras, etc.) et les facteurs pratiques induisant inévitablement de la lipolyse. Pour les études expérimentales, on utilisera des conditions standardisées d'induction (par exemple refroidissement

(2) Ces AGL initiaux représentent généralement des acides gras qui n'ont pas encore été estérifiés par les cellules mammaires, plutôt qu'un produit de la lipolyse. Leur composition en acides gras est très voisine de celle des triglycérides (Bauchart et Chilliard, 1983). 
a) Photographie au microscope électronique $(\times 65000)$ de la section transversale de la membrane de globule gras intact de crème.

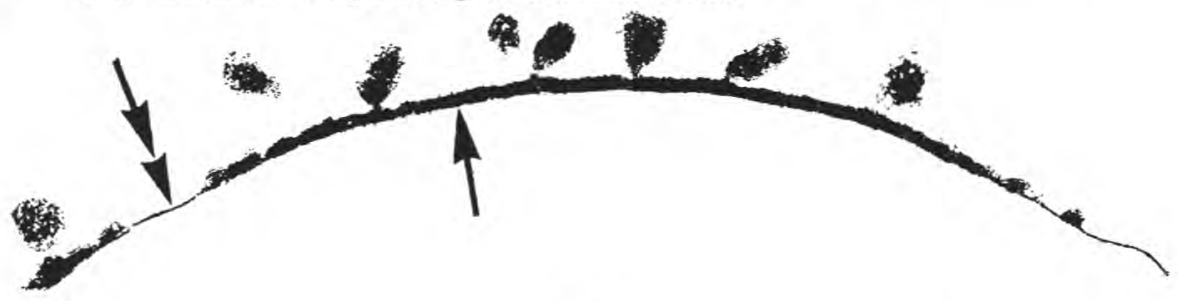

fig. 2

La membrane des globules gras. - Milk fat globule membrane

On peut y voir de petites vésicules provenant de remaniements de la membrane primaire après sécrétion. La flèche simple montre la membrane " primaire ", ici d'épaisseur uniforme, et la double flèche, la membrane "secondaire ». On peut noter la différence de structure.

La membrane "primaire " peut présenter, localement, une épaisseur plus grande ou maintenir occluses des structures cellulaires comme par exemple, des fragments de réticulum endoplasmique (non visibles sur la photographie).

D'après Wooding et Kemp, 1975.

b) Schéma proposé par Mc Pherson et Kitchen, 1983

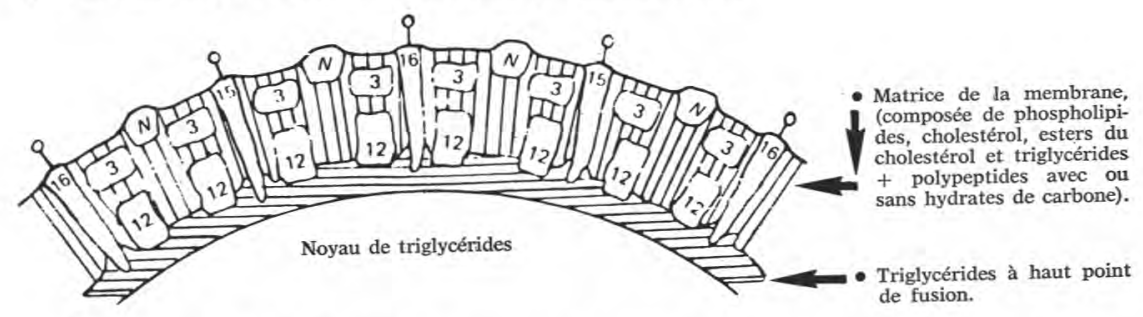

Les polypeptides sont numérotés en utilisant la nomenclature de Mather et Keenan (1975). Les chaînes d'hydrates de carbone sont représentées par de petits cercles sur des extensions de polypeptides 15 et 16 . Le polypeptide $\mathrm{N}$ est la 5 '-nucléotidase ; 3 = xanthine oxydase.

Dans ce schéma, la membrane "secondaire » décrite notamment par Wooding, n'est pas représentée ; mais elle pourrait se situer à la place de la couche " triglycérides à haut point de fusion " dont l'importance est plus ou moins contestée par cet auteur.

rapide à $4^{\circ} \mathrm{C}$ et stockage durant 24 heures, après une traite effectuée avec un matériel déterminé).

$3^{\circ}$ La lipolyse microbienne, qui résulte de l'action des lipases sécrétées par les micro-organismes, essentiellement par les germes psychrotrophes qui constituent l'essentiel de la flore des laits refroidis. Ce type de lipolyse est donc étroitement lié au problème de la qualité bactériologique du lait. 


\section{LES ELEMENTS DU SYSTEME LIPOLYTIOUE}

\section{A. Le substrat : les globules gras (fig. 2)}

Les triglycérides du lait sont sous forme d'une émulsion finement dispersée, représentant une interface matière grasse/eau de 500 à $750 \mathrm{~cm}^{2}$ par millilitre ; mais chaque gouttelette est stabilisée et protégée, en particulier de l'action des lipases, par une «membrane». Cette enveloppe a deux origines : 1) une membrane dite « secondaire », constituée d'une couche de phospholipides et de composés protéiques, entoure les gouttelettes dans la cellule sécrétrice mammaire; sa composition fine et son degré d'organisation ne sont pas encore connus; 2) une membrane "primaire » provenant de la zone apicale de la cellule sécrétrice et/ou des vésicules de Golgi, qui enrobe la gouttelette lors de son expulsion; cette membrane est constituée d'une double couche phospholipidique et de composés protéiques (figure $2 \mathrm{~b}$ ).

Dans le lait alvéolaire, la membrane des globules résulte probablement d'une contraction de cette dernière structure, avec perte de matériel dans la phase aqueuse allant de l'intégrité à l'élimination complète, et adsorption de protéines du lait, d'où l'aspect discontinu, par plaques de la surface des globules (Wooding, 1975). Ceci s'accompagnerait d'un remaniement de la couche «secondaire», et pourrait être à l'origine d'une pellicule résistant aux extractions par le mélange chloroformeméthanol mise en évidence par Wooding et Kemp (1975).

\section{B. Les enzymes}

\section{$1^{\circ}$ LA LiPASE NATURELlE}

La principale lipase sécrétée en grande quantité par les cellules mammaires dans le lait de vache post-colostral est une lipoprotéinelipase (LPL). Cette enzyme intervient dans le métabolisme de l'animal en permettant le prélèvement des lipides sanguins (lipoprotéines) par les cellules mammaires; elle est donc à l'origine de près de $50 \%$ des matières grasses du lait (cf. revue de Chilliard et Sauvant, 1984). Ses caractéristiques moléculaires, son origine cellulaire et son mode d'action dans l'organisme animal, dans le lait ou in vitro, ont été décrits en détail par ailleurs (Olivecrona, 1980 ; Chilliard, 1982). Il faut retenir qu'elle est thermolabile (détruite en $10 \mathrm{sec}$. à $85^{\circ} \mathrm{C}$ ) $(3)$, que son $\mathrm{pH}$ optimum est alcalin (8-9), qu'elle n'agit que faiblement sur les triglycérides à

(3) $\mathrm{D}$ (temps de réduction décimale) $=16$ secondes à $70^{\circ} \mathrm{C}$. Dans les conditions qui existent dans le lait cru refroidi un traitement de 10 secondes à $78^{\circ} \mathrm{C}$ suffit pour stopper l'action de la lipase naturelle. Par contre, une pasteurisation de 10 secondes à $72^{\circ} \mathrm{C}$ ne détruit que $83 \%$ de la LPL et ne permet pas de stopper entièrement la lipolyse dans du lait homogénéisé (Driessen, 1983) et il en est de même si le traitement est prolongé jusqu'à 16 secondes (Shipe et Senyk, 1981). 
longue chaîne en absence de cofacteurs protéiques (du type des apoprotéines C II présentes dans le sang), qu'elle hydrolyse préférentiellement les liaisons ester situées en positions externes sur la molécule de glycérol et qu'elle est inhibée par les concentrations élevées en sels, en AGL ou en protéines, ainsi que par certaines protéines spécifiques à faible concentration.

La spécificité d'action de la LPL pour les positions externes explique que les $\mathrm{AGL}$ produits par la lipase naturelle soient plus riches en acides gras courts $\left(\mathrm{C}_{4}\right.$ à $\left.\mathrm{C}_{8}\right)$ que les triglycérides du lait puisque ces acides gras courts sont surtout estérifiés en position sn-3. Les acides $\mathrm{C}_{4}, \mathrm{C}_{6}, \mathrm{C}_{16.0}$ et $\mathrm{C}_{18.1}$ représentent environ les deux tiers, en mole, des acides gras libérés, les deux premiers en raison de leur libération préférentielle, et les deux derniers en raison de leur forte proportion dans les triglycérides du lait (Bauchart et Chilliard, 1983).

\section{$2^{\circ}$ LES LIPASES LEUCOCYTAIRES}

L'intervention des lipases ou estérases sécrétées par les cellules somatiques (leucocytes notamment) est très mal connue (Deeth et Madsen, 1978). Elles peuvent toutefois être présentes dans le lait en quantité significative (Azzara et Dimick, 1984).

\section{$3^{\circ}$ LES LIPASES MICROBIENNES}

- Flore responsable: Les lipases microbiennes des laits crus réfrigérés proviennent essentiellement de la flore psychrotrophe (bactéries capables de se multiplier suffisamment rapidement et de devenir dominantes à des températures inférieures à $7^{\circ} \mathrm{C}$ ). L'abaissement de la température en dessous de $2^{\circ} \mathrm{C}$ freine considérablement la multiplication de ces bactéries. La plupart de ces dernières sont par ailleurs détruites par pasteurisation et même par une simple thermisation $\left(65^{\circ} \mathrm{C}\right.$ pendant 10 à 15 sec.) (revues de Law, 1979 ; Cousin, 1982 ; Marshall, 1982 ; Choisy et Lenoir, 1984).

Parmi les souches de bactéries psychrotrophes isolées à partir de lait cru et appartenant à divers genres, $70 \%$ ou plus sont capables de produire des lipases ou protéases exocellulaires pouvant nuire à la qualité du lait. Bien que le genre Pseudomonas, avec comme espèce principale $P$. fluorescens, soit très souvent dominant dans les laits conservés à basse température, les comportements des enzymes sécrétées sont loin d'être homogènes.

- Production d'enzymes par les micro-organismes: La présence simultanée de caséines et de protéines du sérum fait du lait un milieu favorable à la production de lipases et de protéases (Rowe et Guilmour, 1983). La production d'enzymes est maximale à des températures voisines de $8^{\circ} \mathrm{C}$ et peut être parfois détectée avant la fin de la phase logarithmique de croissance, même si la production maximale se situe en phase stationnaire (figure 3 ). Ceci signifie que le danger est précoce, que l'allongement de la durée de conservation du lait cru favorise la production d'enzymes, et qu'un même nombre de bactéries n'a pas la même 


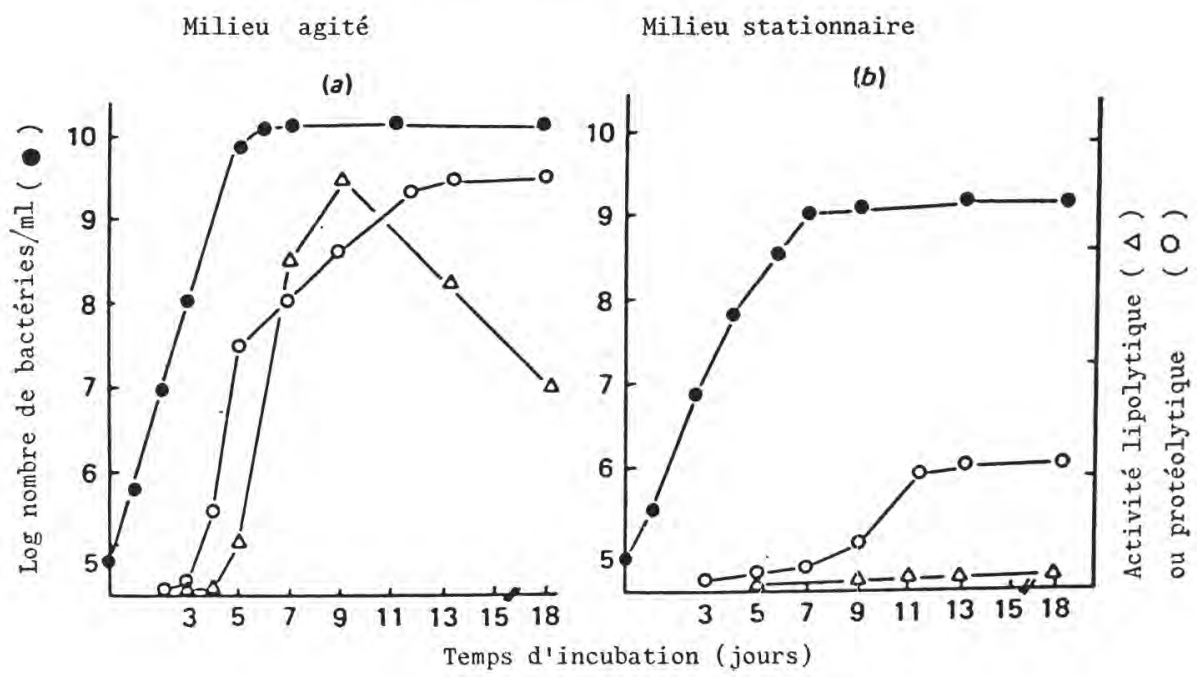

fig. 3

Croissance $(\bullet)$ et productions de protéase $(0)$ et de lipase extracellulaire $(\triangle)$ par $P$. fluorescens AFT 36 dans du lait à $7^{\circ} \mathrm{C}$ (Fox et StePANIAK, 1983).

Growth $(\bullet)$, proteinase production $(0)$ and lipase production $(\triangle)$ by P. fluorescens AFT 36 in milk at $7^{\circ} \mathrm{C}$ under shaken $(a)$ and stationnary $(b)$ conditions.

signification selon qu'elles sont en phase de croissance (peu d'enzymes) ou en phase stationnaire (beaucoup d'enzymes).

- Les pH optimaux d'action se situent entre 6 et 9, mais les valeurs entre 8 et 9 sont les plus fréquemment mentionnées (Fox et Stepaniak, 1983); toutefois l'activité au $\mathrm{pH}$ du lait, sur huile de beurre ou sur crème, peut être de 40 à $50 \%$ de l'activité maximale même lorsque le pH optimal de l'enzyme est élevé (Fitz-Gerald et Deeth, 1983); elle est beaucoup plus réduite lorsque le $\mathrm{pH}$ est abaissé à 6,5 ou $6,0(10 \%$ ou moins).

- Les températures optimales d'action sont de 30 à $40^{\circ} \mathrm{C}$ et parfois de $50^{\circ} \mathrm{C}$. Pour certaines souches, l'effet de la température serait complexe et deux énergies apparentes d'activation ont été calculées, l'une de 25 à $37^{\circ} \mathrm{C}$, l'autre de 39 à $50^{\circ} \mathrm{C}$ (Driessen et Stadhouders, 1974). $\mathrm{Au}$ delà de $50^{\circ} \mathrm{C}$, l'activité est en général bien diminuée. Cependant Mortensen et Jansen (1982) recommandent la température de $55^{\circ} \mathrm{C}$ pour la détermination des activités lipolytiques résiduelles dans les crèmes et les beurres. A $4-10^{\circ} \mathrm{C}$, l'activité est réduite mais non négligeable. Dans le lait, elle serait à $10^{\circ} \mathrm{C}$ de 20 à $25 \%$ de l'activité maximale (Te Whaiti et Fryer, 1978). Mais, pour une souche de P. fluorescens, Landass et Solberg (1978) signalent que l'activité à $1^{\circ} \mathrm{C}$ sur tributyrine représente encore $30 \%$ de l'activité maximale. 
- Substrats : Les lipases des psychrotrophes manifestent une hydrolyse plus rapide sur les triglycérides homogènes dont les acides gras ont des chaînes courtes ou moyennes ou insaturées. Mais il existe aussi des différences importantes entre les espèces, et même au sein d'une espèce, dans les rapports d'hydrolyse de ces divers triglycérides. Sur les graisses et huiles naturelles, l'action est un peu moins rapide et très variable d'une souche à l'autre selon le substrat.

Dans le cas de l'hydrolyse d'une matière grasse butyrique, il y a peu de données sur les proportions relatives des acides gras libérés. On peut rapporter les résultats de Landass et Solberg (1978) qui font état, lors d'essais d'addition de lipase d'une souche de $P$. fluorescens à du lait stérilisé, d'une libération plus importante d'acides gras à courte chaîne et ceci est d'autant plus marqué que la température de conservation est basse; ce phénomène est particulièrement net, d'après ces auteurs, pour l'acide butyrique. Avant de parler de spécificité proprement dite, il faut remarquer que peu de choses sont connues de l'influence de l'état physique des triglycérides sur leur vitesse d'hydrolyse par les lipases mais on peut penser qu'elle est ralentie lorsque les triglycérides sont sous forme cristallisée. Si bien que les acides gras courts ou les acides gras longs insaturés, qui abaissent le point de fusion des triglycérides, sont aussi ceux qui risquent le plus d'être libérés ; cela viendrait s'ajouter à une éventuelle préférence pour les positions externes ou les acides gras courts.

- Stabilité thermique: La revue bibliographique de Cogan (1977) et le tableau présenté par Fox et Stepaniak (1983) rapportent les stabilités thermiques de lipases de diverses espèces et souches ainsi que les valeurs de $\mathrm{D}$ et de $\mathrm{Z}$ (variation de température modifiant la valeur de $\mathrm{D}$ d'un facteur 10). La thermorésistance est une propriété fréquente mais non générale des lipases des bactéries psychrotrophes. Un certain nombre de souches produisent des lipases qui ne sont que partiellement inactivées dans les conditions de pasteurisation des laits $\left(72^{\circ} \mathrm{C}, 15 \mathrm{~s}\right)$ ou de stérilisation UHT $\left(140^{\circ} \mathrm{C}\right.$ quelques secondes) (Muir et Phillips, 1984). Mais les taux d'inactivation sont très variables selon les espèces (par exemple 5 à $80 \%$ d'activité résiduelle après $5 \mathrm{~s}$ à $140^{\circ} \mathrm{C}$ : Griffiths et al., 1981) et selon les souches d'une même espèce. La composition du milieu peut jouer un rôle et le lait peut contribuer à augmenter la stabilité de certaines lipases en raison de sa richesse en calcium (O'Donnell, 1978).

Un certain nombre de travaux ont mis en évidence des déstabilisations importantes des lipases à température relativement basse avec une meilleure stabilité aux températures plus élevées ; mais toutes les lipases des différentes souches n'ont pas ce comportement. Les zones d'instabilité se situent à $40-50^{\circ} \mathrm{C}$ (Marshall, 1982) ou $55^{\circ} \mathrm{C}$ (Griffiths et al., 1981 ; Fitz-Gerald et al., 1982). Ce phénomène n'est pas simple à expliquer et pourrait correspondre à l'existence de plusieurs conformations de la même enzyme (Driessen, 1983) ; il a été également constaté à $60-70^{\circ} \mathrm{C}$ pour une fraction purifiée d'une lipase de $P$. fluorescens (Fox 
et Stepaniak, 1983). Toutefois, d'un point de vue pratique, cette propriété ne peut être exploitée car elle n'est pas générale et souvent la dégradation de l'enzyme n'est pas totale. De plus, comme le font remarquer Fitz-Gerald et al. (1982) le maintien du lait à des températures dépassant $40^{\circ} \mathrm{C}$ pendant des temps prolongés pourrait entraîner des dégradations enzymatiques très importantes (protéolyse, ...).

Un chauffage bref à une température supérieure à $90^{\circ} \mathrm{C}$ peut parfois augmenter la stabilité des lipases vis-à-vis d'un chauffage ultérieur à des températures plus basses, ou même provoquer une légère augmentation de l'activité (Anderson et al., 1979).

Driessen et Stadhouders (1974) ont mis en évidence l'aspect biphasique que peuvent avoir les cinétiques de déstabilisation thermique des lipases; la seconde phase correspond alors à une perte relativement lente d'activité. Ce même comportement a été signalé aussi bien lorsque les enzymes sont chauffées dans le lait (Adams et Brawley, 1981), que pour une solution d'enzyme purifiée (Fox et Stepaniak, 1983).

Etant donné la très grande variété des propriétés des enzymes non seulement selon les espèces mais souvent même selon les souches, en particulier pour les Pseudomonas, toutes les extrapolations de résultats semblent hasardeuses. Ceci nécessite des expérimentations répétées en vraie grandeur et dans des situations variées avant de pouvoir conclure, car de faibles activités résiduelles, même si les conditions d'action ne sont pas optimales, peuvent avoir des effets lipolytiques marqués à long terme.

$4^{\circ}$ LES AUTRES ENZYMES POUVANT JOUER UN RÔLE DANS LA LIPOLYSE

On considère habituellement que d'autres enzymes peuvent jouer un rôle indirect dans la lipolyse; ce sont essentiellement :

- Des enzymes lipogéniques diverses qui interviennent soit dans la synthèse, soit dans l'estérification des acides gras. Elles sont naturellement sécrétées par la mamelle et résultent du passage dans le lait de fragments de cytoplasme et d'organites cellulaires. En outre les leucocytes pourraient aussi avoir une activité lipogénique d'estérification (revue de Chilliard, 1982). Ces enzymes peuvent donc modifier les teneurs en AGL du lait. L'importance quantitative de leur action et leur durée de vie sont probablement faibles (mais mal connues). Leur rôle dans les variations de la lipolyse est probablement restreint aux premières heures de stockage du lait, mais pourrait expliquer certaines « anomalies » des cinétiques d'évolution des AGL pendant cette période, rapportées dans plusieurs expériences.

- Des protéases : Il existe des protéases naturelles du lait (la principale étant la plasmine d'origine sanguine) auxquelles peuvent s'ajouter des protéases leucocytaires et des protéases microbiennes produites par la flore psychrotrophe (revue de Miranda et Gripon, 1984). Hoffmann et al. (1979) ont montré qu'une partie des protéases naturelles est liée à la membrane du globule gras intervenant peut-être dans la transformation de celle-ci. 
- Des phospholipases : La présence de phospholipase naturelle dans le lait fraîchement sécrété ne semble pas avoir été montrée. En revanche, près de la moitié des souches parmi les bactéries psychrotrophes isolées par Fox et al. (1976) à partir de lait cru ou pasteurisé, appartenant surtout aux genres Bacillus et Pseudomonas, produit une phospholipase C. Cette enzyme hydrolyse la liaison ester entre le glycérol et l'acide phosphorique, libérant ainsi un 1,2-diglycéride et la phosphorylcholine. En outre, d'autres enzymes bactériennes (phospholipase $\mathrm{A}_{1}$, lysophospholipase $\mathrm{C}$, lipase) poursuivent l'hydrolyse des phospholipides, selon un schéma variable avec la souche (Deeth, 1982). Certaines phospholipases sont fortement thermorésistantes (Griffiths, 1983).

- Des glucosidases : Marin et al. (1984) ont montré qu'une enzyme produite par $P$. fluorenscens 26 pouvait hydrolyser les glycocomplexes (glycoprotéines ou glycolipides) du lait écrémé, du babeurre, de la crème ou de la membrane des globules gras. Sur 19 souches de bactéries psychrotrophes, 4 seulement n'hydrolysent pas les glucosides de synthèse, 9 le font faiblement et 6 , dont 4 souches du genre Enterobacter, sont très actives (Marin et Marshall, 1983).

Ces trois catégories d'enzymes peuvent jouer un rôle dans les remaniements ou les dégradations des membranes des globules gras puisque l'intégrité des protéines, des phospholipides et des glycoprotéines conditionnent le rôle de barrière de la membrane. L'action des protéases sur les caséines (solubilisation de la lipase ?) pourrait aussi modifier la lipolyse.

\section{MECANISMES D'ACTION DES LIPASES DANS LE LAIT}

\section{A. Action de la lipase naturelle (LPL) dans le lait refroidi}

Il n'y a généralement pas de liaison entre la quantité totale de lipase présente dans le lait de vache, et la lipolyse «spontanée». En effet l'action de la lipase dépend de nombreux facteurs dont certains sont liés aux propriétés du lait natif, c'est-à-dire à la physiologie de l'animal (Olivecrona, 1980 ; Chilliard, 1982).

L'action des lipases sur la matière grasse du lait obéit aux lois générales de la cinétique enzymatique. Elle est toutefois compliquée par le fait que le substrat lipidique est insoluble, et que la concentration effective en substrat s'exprime en terme de surface de l'interface huileeau. Dans le cas du lait, l'interaction enzyme-substrat peut être modifiée par la présence de la membrane des globules gras, et par les liaisons entre la lipase et les micelles de caséine.

La réaction générale est la suivante : $\mathrm{E}+\mathrm{S} \rightleftarrows \mathrm{ES} \rightarrow \mathrm{E}+\mathrm{P}$, où $\mathrm{E}=$ enzyme (lipase), $\mathrm{S}=$ substrat (triglycérides des globules) et $\mathrm{P}=$ produits (AGL et glycérides partiels). La première étape (1) est donc la 
liaison lipase-triglycérides, qui peut elle-même être précédée par une liaison préalable lipase-globules gras ou lipase-membrane des globules gras. La deuxième étape (2) est la catalyse enzymatique proprement dite.

\section{$1^{\circ}$ Liaison lipase-globules gras}

La proportion de la lipase totale liée aux globules gras varie de $5 \%$ dans le lait natif à plus de $50 \%$ après induction de lipolyse, et elle est assez bien corrélée à la lipolyse (Castberg et al., 1975; Deeth et Fitz-Gerald, 1977; Wang et Randolph, 1978; Bachman, 1982; Sundheim et al., 1983). La liaison lipase-globule gras et le déplacement de l'équilibre " caséines lipases globules gras » varient avec les facteurs physiologiques ( $§ \mathrm{VI} \mathrm{A}$ ) et sont probablement modulés par le $\mathrm{pH}$ et les concentrations en héparinoïdes, en sels et en activateurs ou inhibiteurs protéiques ou lipoprotéiques (Bengtsson et Olivecrona, 1982; 1983 ; Sundheim et al., 1983) (tableau 1).

\section{$2^{\circ}$ Activité DE LA LiPASE LIÉE A LA CRÈME}

Une fois liée aux globules gras, la lipase semble plus résistante à l'inactivation (P. Cartier et Y. Chilliard, non publié) et son activité varie avec les conditions qui prévalent dans le lait :

- la température : l'activité augmente avec la température mais la durée de vie de l'enzyme diminue. Ainsi, à $4^{\circ} \mathrm{C}$, l'enzyme agit moins vite mais conserve plus longtemps son activité ;

- le $\mathrm{pH}$ du lait : l'activité augmente si le pH s'élève (Murphy et al., 1979);

- la présence de cofacteurs lipoprotéiques (Clegg, 1980 ; Sundheim et al., 1983 ; tableau 1) ou protéiques (Bengtsson et Olivecrona, 1982). Bien que l'action de tels cofacteurs exogènes soit spectaculaire, la présence et l'action sur la lipolyse de cofacteurs naturellement présents dans le lait (Murphy et al., 1979) n'ont pas encore été établies de façon indiscutable ;

- la concentration en AGL à la périphérie des globules gras (interface huile-eau). Ceux-ci inhibent la lipase ; or leur concentration diminue localement si le lait est agité (Downey, 1980), ou si des protéines ou des ions calcium fixent les AGL. Les activateurs protéiques pourraient d'ailleurs agir en rompant les liaisons lipase-AGL (Vainio et al., 1982);

- la composition et l'état d'altération de la membrane des globules gras (cf. $\S \mathrm{V} \mathrm{B}, \mathrm{V} \mathrm{C}$ et tableau 1 ).

Les résultats du tableau 1 montrent qu'il est possible d'agir expérimentalement à différents niveaux de façon séparée. Ainsi, l'héparine augmente la lipolyse en modifant la répartition de la lipase, mais pas l'état du substrat, ni l'activité de la lipase liée. Les cofacteurs sanguins modifient à la fois la répartition et l'activité catalytique de la lipase liée aux globules, alors que les membranes des globules gras ne sont probablement pas dégradées. Les facteurs mécaniques et thermiques (voir § V B) 


\section{TABLEAU 1}

Influence de différents traitements sur l'évolution de la teneur en AGL (lipolyse) du lait et sur la teneur en lipase de la crème (activité potentielle dans les conditions optimales in vitro)

Effect of various treatments on increase of milk free fatty acids (lipolysis) and on lipoprotein lipase activity in the cream (potential activity as measured in vitro)

(P. Cartier et Y. Chilliard, non publié)

\begin{tabular}{|c|c|c|c|c|c|c|}
\hline & \multirow{2}{*}{ Traitement d'induction de lipolyse } & \multicolumn{2}{|c|}{$\begin{array}{c}\text { Lipolyse } \\
\text { ( } \mu \text { eq } \mathrm{AG} / 22 \mathrm{~h} / 100 \mathrm{~g} \text { MG) }\end{array}$} & \multicolumn{2}{|c|}{$\begin{array}{l}\text { Activité LPL liée à la crème (1) } \\
\text { (ueq AG/h/g crème) }\end{array}$} & \multirow{2}{*}{$\begin{array}{l}\text { Lipolyse par } \\
\text { unité de LPL } \\
\text { liée à la crème }\end{array}$} \\
\hline & & $\begin{array}{l}\text { Valeur } \\
\text { absolue }\end{array}$ & $\begin{array}{l}\text { Valeur } \\
\text { relative }\end{array}$ & $\begin{array}{c}\text { Valeur } \\
\text { absolue }\end{array}$ & $\begin{array}{l}\text { Valeur } \\
\text { relative }\end{array}$ & \\
\hline \multirow{3}{*}{ 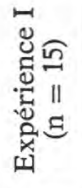 } & Témoin & $472 \pm 366$ & 1.0 & $66 \pm 50$ & 1.0 & $8.0 \pm 4.2$ \\
\hline & Vortex (30s) & $814 \pm 492$ & $1.9 \pm 0.5$ & $78 \pm 53$ & $1.3 \pm 0.4$ & $11.4 \pm 4.8$ \\
\hline & Polytron (15s) & $2204 \pm 713$ & $6.2 \pm 3.3$ & $136 \pm 61$ & $2.5 \pm 1.4$ & $18.7 \pm 6.4$ \\
\hline \multirow{5}{*}{ 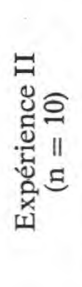 } & Témoin & $369 \pm 219$ & 1.0 & $63 \pm 20$ & 1.0 & $5.5 \pm 1.9$ \\
\hline & Sérum sanguin $10 \%(\mathrm{v} / \mathrm{v})$ & $6865 \pm 2014$ & $23.7 \pm 13.1$ & $277 \pm 74$ & $4.7 \pm 1.6$ & $25.1 \pm 5.2$ \\
\hline & Héparine (1 UI/ml) & $1511 \pm 901$ & $4.2 \pm 1.1$ & $247 \pm 90$ & $3.9 \pm 1.0$ & $5.9 \pm 1.8$ \\
\hline & $5 \rightarrow 15 \rightarrow 4^{\circ} \mathrm{C}(2)$ & $880 \pm 517$ & $2.4 \pm 0.5$ & $120 \pm 73$ & $1.8 \pm 0.8$ & $7.7 \pm 2.2$ \\
\hline & $5 \rightarrow 30 \rightarrow 4^{\circ} \mathrm{C}$ & $2755 \pm 1459$ & $8.1 \pm 3.5$ & $209 \pm 98$ & $3.2 \pm 1.1$ & $13.4 \pm 3.4$ \\
\hline
\end{tabular}

Les traitements sont effectués sur du lait frais, non refroidi, dans les 10 min qui suivent la traite. Les mesures sont effectuées après incubation pendant $22 \mathrm{~h}$ à $4^{\circ} \mathrm{C}$ (moyenne \pm écart-type).

(1) Activité LPL des laits entiers, expérience I : $64 \pm 28$, expérience II : $105 \pm 32$ ( $\mu$ eq AG/h/ml lait).

(2) Traitement thermique : refroidissement $\left(\grave{a} 5^{\circ} \mathrm{C}\right.$ ) et réchauffement rapides du lait (à $15^{\circ} \mathrm{C}$ ou $30^{\circ} \mathrm{C}$ ), puis refroidissement à $4^{\circ} \mathrm{C}$. 
modifient à la fois la quantité de lipase liée à la crème (4) et, dans certains cas, l'état des membranes ou la structure des globules gras.

S'il est bien établi que la quantité de lipase liée à la crème et l'intégrité des globules gras sont des facteurs importants pour la lipolyse, l'existence et le rôle exact dans le lait des différents facteurs susceptibles de modifier la répartition et l'activité de la lipase (pour un état donné des globules gras) sont loin d'être entièrement connus. Ainsi la fraction 3 des protéoses-peptones qui proviendrait de la membrane des globules gras (Kester et Brunner, 1982) pourrait inhiber la lipolyse (Anderson, 1981) et la LPL (P. Cartier et Y. Chilliard, non publié) par un mécanisme inconnu. Les protéases pourraient aussi empêcher l'action d'éventuels activateurs lipoprotéiques (Anderson, 1983). La présence d'inhibiteurs dans les laits normaux pourrait par ailleurs expliquer que la lipolyse spontanée soit généralement réduite dans les laits de mélange. Par contre, ces inhibiteurs ne semblent pas ralentir la lipolyse induite.

\section{B. Effets de différentes inductions thermiques et mécaniques sur la lipolyse}

Il est bien connu que l'homogénéisation du lait entraîne une augmentation de la lipolyse; la taille des globules gras diminue si bien que la surface peut être multipliée par 6 ou 10 et la nouvelle "membrane » qui se forme sur la matière grasse ne protège plus aussi efficacement les triglycérides de l'action des lipases (5). Des traitements bien moins radicaux - agitation modérée mais surtout aération - peuvent aussi activer la lipolyse mais la nature exacte des modifications induites par ces traitements n'est souvent pas connue; la température y joue un rôle très important.

\section{$1^{\circ}$ EFFET GLOBAL SUR LA LIPOLYSE}

De nombreuses études ont été réalisées depuis les années trente (Krukovsky et Herrington, 1939...) sur l'activation thermique et/ou mécanique de la lipolyse dans des conditions de laboratoire. La plupart ont été passées en revue par Fleming (1979). Le phénomène est très complexe et certains résultats sont contradictoires ou inexpliqués.

L'activation de la lipolyse varie avec différents facteurs qui interagissent :

- l'âge et le passé thermique (variations de température) du lait,

- la nature du traitement mécanique (agitation, homogénéisation), son intensité (vitesse, pression, ...), sa durée, la température à laquelle il est appliqué, et le degré d'aération (moussage),

(4) Il s'agit ici de la crème du lait obtenue par centrifugation à froid en tubes à essai.

(5) D'où le risque de mélanger des laits homogénéisés avec des laits insuffisamment pasteurisés contenant des taux significatifs de LPL résiduelle. 
- les caractéristiques intrinsèques du lait (animal, ...).

Les principales conclusions sont les suivantes :

- la lipolyse est plus forte en cas de refroidissement lent, avec une zone critique de température entre 15 et $25^{\circ} \mathrm{C}$. Toutefois, la lipolyse spontanée peut parfois être réduite si le lait reste quelques heures à température ambiante avant d'être refroidi ;

- la séquence « refroidissement $\left(0-10^{\circ} \mathrm{C}\right) /$ réchauffement (15$\left.30^{\circ} \mathrm{C}\right) /$ refroidissement $\left(5-10^{\circ} \mathrm{C}\right) »$ induit de fortes lipolyses, le maximum étant souvent atteint pour le cycle $\left(0-30-5^{\circ} \mathrm{C}\right)$; cet effet ne semble pas être additif avec celui des traitements mécaniques du type homogénéisation ;

- l'activation de la lipolyse est minimale lorsque les traitements mécaniques sont appliqués à $5-10^{\circ} \mathrm{C}$; elle augmente très rapidement entre 10 et $25^{\circ} \mathrm{C}$, et plus lentement jusqu'à $35-40^{\circ} \mathrm{C}$. On observe toutefois un véritable pic de sensibilité lorsque l'activation mécanique est effectuée aux alentours de $15^{\circ} \mathrm{C}$, avec une diminution à $20^{\circ} \mathrm{C}$, dans le cas d'une agitation lente et de courte durée avec incorporation d'air et moussage, sur des laits frais, ayant un taux butyreux supérieur à $3 \%$ et incubés ultérieurement à basse température $\left(5-10^{\circ} \mathrm{C}\right)$ (Deeth et FitzGerald, 1977) ;

- le lait préalablement refroidi à $0-5^{\circ} \mathrm{C}$ pendant 2 à $4 \mathrm{~h}$ est particulièrement sensible à l'activation mécanique ;

- les traitements d'activation ont généralement des effets plus marqués sur les laits qui lipolysent spontanément;

- l'augmentation des teneurs en AGL est très rapide, et se réalise en grande partie dans les minutes qui suivent certains traitements d'induction.

\section{$2^{\circ} \quad$ ACTION SUR LES GLOBULES GRAS}

La lipolyse est souvent considérée comme un phénomène se produisant après une détérioration préalable de la membrane du globule gras, mais il est difficile d'évaluer cette détérioration dont la nature et l'ampleur peuvent être très diverses. De plus, il est possible qu'elle n'ait pas la même importance pour toutes les lipases : ainsi Fitz-Gerald \& Deeth (1983) suggèrent que les lipases des psychrotrophes puissent agir sans détérioration de la membrane mais leur action souvent tardive (post-fabrication) rend ce point beaucoup moins important que pour la lipase naturelle du lait.

La détérioration des membranes des globules gras semble résulter à la fois de facteurs externes (chocs mécaniques, aération) et internes aux globules (cristallisation de la phase grasse), et de leurs interactions.

Ainsi, un refroidissement lent est néfaste dans la zone critique de 15 à $25^{\circ} \mathrm{C}$ car il favorise la formation de gros cristaux lipidiques (triglycérides à haut point de fusion) qui coexistent avec des triglycérides à l'état liquide. La disposition et le mouvement de ces cristaux à la 
périphérie des globules gras favorisent les altérations de leur membrane et diminue la stabilité de l'émulsion (agrégation) (Walstra, 1978). La fluidité des matières grasses insaturées les rendrait par ailleurs plus sensibles à la lipolyse (Kirst et Westphal, 1983).

Dans le cas des traitements à haute énergie et à température élevée, on a plutôt un éclatement des globules gras contenant une matière grasse fluide (homogénéisation) accompagné d'une redistribution du matériel membranaire et d'une adsorption de caséines et de protéines sériques à la surface des nouveaux globules.

Dans le cas de moussage, les remaniements de matériel membranaire peuvent être très importants par étalement sur les bulles d'air, du fait des tensions de surface à l'interface air-liquide qui déforment les globules gras; ce qui pourrait conduire, lorsque les globules gras sont fluides et que les bulles éclatent, à une homogénéisation limitée dans le lait frais (Anderson, 1983; Marshall, 1983) et à un accroissement de la surface du substrat suffisant pour induire la lipolyse.

Lors de traitements à basse énergie, il se produit plutôt des phénomènes d'agrégation des globules gras, notamment aux alentours de la température de $15^{\circ} \mathrm{C}$ où coexistent des triglycérides fluides et cristallisés en proportions variables selon le passé thermique du lait (refroidi ou non à $4^{\circ} \mathrm{C}$ au préalable). Au cours de la conservation à $4^{\circ} \mathrm{C}$, il se produit une désorption de constituants membranaires (phospholipides, protéines) qui augmente probablement la sensibilité des globules gras à l'induction mécanique de lipolyse, bien que la cristallisation des triglycérides leur ait conféré une rigidité suffisante pour limiter l'homogénéisation et le barattage.

Il existe probablement des différences entre les globules gras des laits individuels quant à leur aptitude à résister aux traitements mécaniques ou à l'aération mais les preuves n'en ont pas été apportées. A fortiori, l'incidence de la composition de leur membrane sur la stabilité plus ou moins grande des globules gras n'est pas connue.

L'augmentation de lipolyse due à la lipase naturelle du lait sous l'action de différents traitements mécaniques et thermiques est assez bien corrélée avec la lipolyse provoquée par addition d'une lipase microbienne mais non avec la quantité de matière grasse extractible par l'hexane (appelée parfois matière grasse "libre »), ni avec les teneurs en lipides et en phosphatase alcaline (6) du lait écrémé (Deeth et Fitz-Gerald, 1978 ; Anderson, 1982). Dans ces expériences, toutes les mesures directes de l'état des globules gras (matière grasse "libre » et matériel membranaire) sont donc peu reliées à la lipolyse résultant des traitements d'activation. Par contre, Bhavadasan et al. (1982) trouvent une liaison entre l'induction de lipolyse et le relargage de la xanthine oxydase membranaire (6).

(6) Enzyme de membrane dont la désorption peut être considérée comme témoin de la dégradation de celle-ci. 
Il semble qu'en fait les traitements qui s'accompagnent de remaniements membranaires (homogénéisation, aération) entraînent systématiquement une lipolyse accrue, alors que ce n'est pas toujours le cas avec les traitements qui produisent des phénomènes d'agrégation (grains de beurre) et de coalescence (remontée d'huile) (Anderson, 1983). Il est donc abusif d'envisager une relation directe entre altération visible des globules gras (ou matière grasse « libre ») et lipolyse. En réalité, seules les altérations qui accroissent l'interaction entre les triglycérides des globules gras et les lipases sont à considérer dans le cas de la lipolyse. On peut en citer pour preuve le fait que certaines inductions thermiques sont réversibles, donc indépendantes d'une altération au sens strict des globules gras.

\section{$3^{\circ}$ INFLUENCE SUR L'INTERACTION LIPASE-MATIÈRE GRASSE}

La liaison lipase-globules gras est en effet accrue par les traitements thermiques de refroidissement simple, et surtout les cycles de refroidissement - réchauffement-refroidissement (Wang et Randolph, 1978; tableau 1). Cette liaison augmenterait dans le cas des laits à fort taux butyreux, mais serait partiellement réversible par simple réchauffement (Wang et Randolph, 1978); elle résulterait de modifications des propriétés des globules gras intacts en cours de solidification.

L'activation mécanique de la lipolyse entraîne par ailleurs un déplacement de la lipase vers les globules gras, en particulier dans le cas du lait chaud $\left(37^{\circ} \mathrm{C}\right.$ ) et dans le cas du lait refroidi à $5^{\circ} \mathrm{C}$ (Deeth et FitzGerald, 1977), de façon variable selon la durée et les conditions d'agitation (tableau 1). La migration de la lipase pourrait être facilitée à la fois par l'augmentation de la surface disponible sur les globules gras et des échanges membrane-plasma, et par l'intensification des phénomènes de diffusion (Schwartz, 1974).

Les résultats du tableau 1 montrent que, dans le cas d'inductions mécaniques à basse énergie sans moussage (Vortex) ou à haute énergie avec incorporation d'air (Polytron), il y a parallélisme entre les augmentations de la liaison lipase-globules gras, et de la lipolyse par unité de lipase liée. Ceci suggère que la liaison de la lipase aux globules gras est en partie proportionnelle aux dégâts causés aux membranes de ceuxci, contrairement à ce qui se passe par exemple dans le cas de l'activation par l'héparine.

Enfin, les mécanismes de liaisons entre les lipases microbiennes et les globules gras et les conditions de leur action ultérieure sont encore très mal connus et probablement très variables selon les espèces bactériennes ( $§$ IV B 3) et selon le type de produit. Ainsi, dans le beurre, la phase aqueuse contient un complexe lipoprotéique provenant probablement d'une interaction entre des fragments de globules gras et des protéines du lait dénaturées par la chaleur. Ce complexe lipoprotéique contient des acides gras à courte chaîne et semble être un excellent substrat pour les lipases des psychrotrophes (McPherson et al., 1981). 


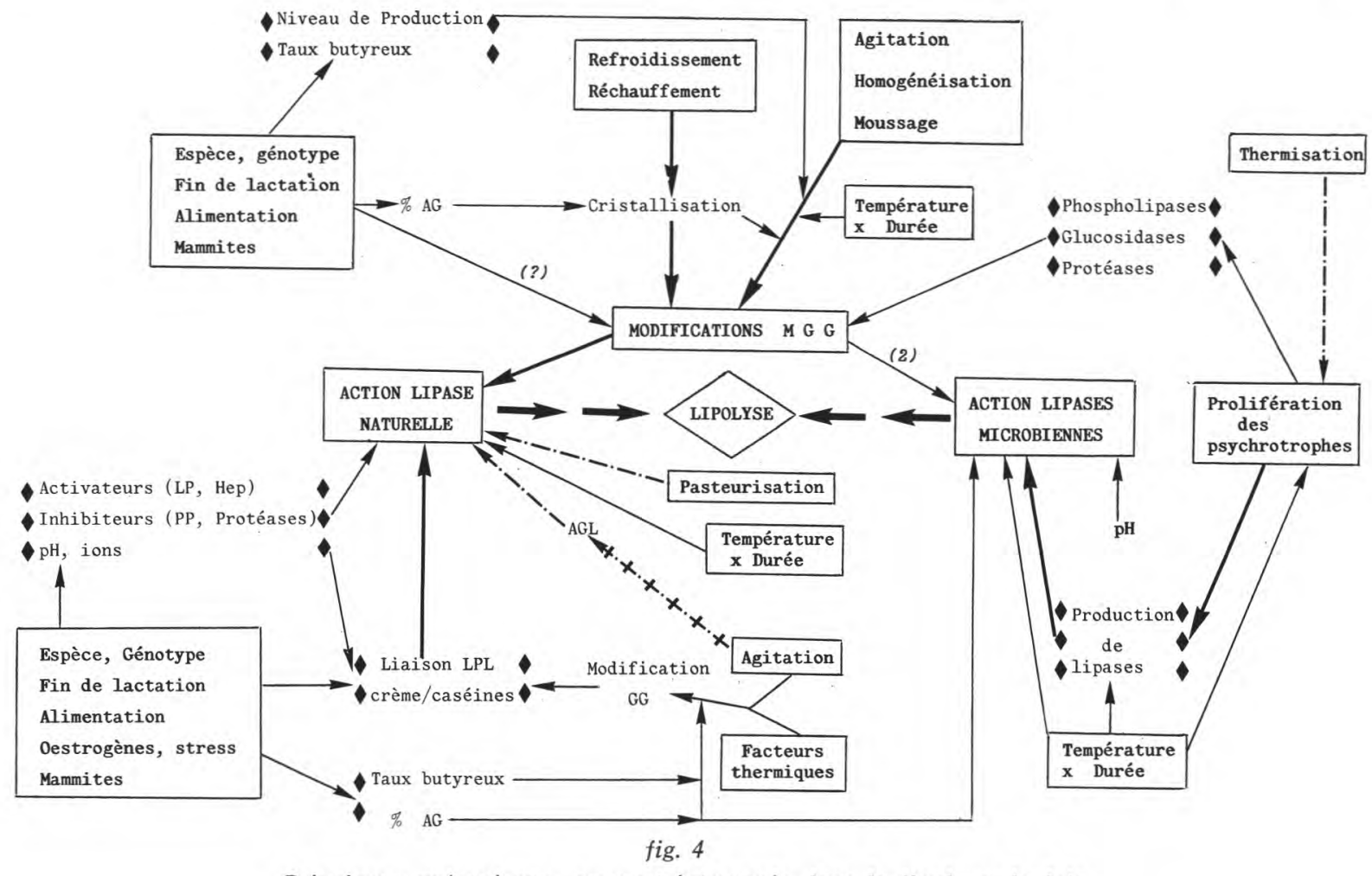

Principaux mécanismes pouvant intervenir dans la lipolyse du lait Possible mechanisms of milk lipolysis

(1) Ou «facteur animal ».

(2) Certaines lipases agissent sans modification préalable des MGG.

Abréviations :

$\% \mathrm{AG}=$ Composition en acides gras des matières grasses $; \mathrm{GG}=$ Globules gras ; MGG = Membrane des GG ; Hep $=$ Héparinoïdes $; \mathrm{LP}=$ Lipoprotéines $; \mathrm{PP}=$ Protéoses-peptones.

Température $x$ durée $=$ Conditions de stockage.

Afin de simplifier, nous avons notamment omis dans ce schéma l'influence des mammites sur les AGL initiaux, et les influences hypothétiques des diverses enzymes leucocytaires (voir le texte).

$-\ldots \rightarrow$ Inhibition $\quad++++$ Levée d'inhibition $\rightarrow$ Influence positive ou négative. 
Au total, il ressort clairement de ce qui précède qu'il est illusoire de penser pouvoir expliquer les variations de lipolyse à l'aide de quelques paramètres seulement! (Figure 4.)

\section{Action des phospholipases et des protéases sur la membrane - des globules gras et sur la lipolyse}

La présence d'une phospholipase $C$ de $P$. fluorescens peut faciliter l'action de la LPL et augmenter le taux d'AGL dans le lait cru (Chrisope et Marshall, 1976). L'effet est comparable à celui d'une homogénéisation et il n'y a pas de synergie entre les deux (Griffiths, 1983). Le rôle activeur de la phospholipase est plus faible avec la lipase de la moisissure Rhizopus arrhizus et nul avec une lipase de Pseudomonas (Griffiths, 1983), ce qui confirme le caractère très agressif de certaines lipases microbiennes, puisqu'elles peuvent agir sur des globules gras peu endommagés (G. Lamberet, données non publiées).

Les protéines de la membrane peuvent être aussi hydrolysées, mais à des degrés variables selon le type de protéase. La papaïne ou la Pronase qui attaquent les glycoprotéines membranaires n'augmentent la lipolyse dans le lait qu'en présence de phospholipase C tandis que la trypsine qui n'attaque pas les glycoprotéines aurait plutôt tendance à la diminuer (Griffiths, 1983). De telles études n'ont pas encore été réalisées avec les glucosidases.

La résistance des globules gras à des traitements mécaniques ou à l'aération lorsque les composants de leur membrane sont partiellement hydrolysés ne semble pas non plus avoir été contrôlée. L'importance pratique de ces actions enzymatiques est donc très difficile à estimer avec les données disponibles, tant en ce qui concerne la stabilité des globules gras que la lipolyse proprement dite.

\section{FACTEURS PRATIQUES DE VARIATION DE LA LIPOLYSE DANS LE LAIT}

\section{A. Facteurs liés à l'animal et aux conditions d'élevage}

Ces facteurs ont été décrits en détail par Jellema (1980) et Chilliard (1982) et ne seront que brièvement rappelés en privilégiant les publications récentes.

\section{$1^{\circ}$ EsPÈce ANimALE}

Il existe d'importantes variations entre espèces. Ainsi, la lipoprotéine-lipase du lait natif est presque entièrement liée à la crème chez la femme (Hernell et Olivecrona, 1974) et pour moitié chez la chèvre (Chilliard et al., 1984). Il en résulte que chez ces deux espèces la lipolyse «spontanée » est fortement ou assez fortement corrélée à la quantité totale de lipase sécrétée (Luzeau et al., 1975 ; Chilliard et al., 1981) 
et que les facteurs physiologiques n'ont pas le même effet que chez la vache.

Ainsi, chez la chèvre, activité lipasique et lipolyse du lait varient parallèlement avec le génotype, sont maximum en pleine lactation (et non en fin de lactation comme chez la vache), sont diminuées par le jeûne et la distribution de lipides insaturés sous forme protégée (Chilliard et al., 1981). Il est à noter que certains acides gras courts $\left(\mathrm{C}_{6}\right.$ et $\mathrm{C}_{8}$ ) contribuent à donner le goût " chèvre » des produits laitiers caprins.

Alors qu'il existe quelques données sur la lipase du lait de bufflonne, on ignore presque tout de celle du lait de brebis, qui semblerait assez résistant à la lipolyse d'après les résultats préliminaires de $\mathrm{P}$. Le Mens et J. C. Le Jaouen (Communication personnelle). Les globules gras du lait de bufflonne seraient plus fragiles et sensibles à la lipolyse induite que ceux du lait de vache (Bhavadasan et al., 1982). Le lait de jument est riche en lipoprotéine-lipase (Chilliard et Doreau, 1985) mais la lipolyse n'a pas été étudiée chez cette espèce.

\section{$2^{\circ} \quad$ RACE}

Chez les bovins, l'effet race ne semble pas être important. On signale parfois un effet génétique (ou un effet animal répétable d'une lactation à l'autre) intra-race. Un tel effet génétique n'a toutefois pas été confirmé par Winter et al. (1981).

\section{$3^{\circ}$ Stade de Lactation eT NiveAu DE PRODUCtion}

La lipolyse est généralement plus élevée chez les vaches en fin de lactation, chez les faibles productrices (moins de 5 à $10 \mathrm{~kg} / \mathrm{j}$ ), et dans le lait de la traite du soir. Cet effet pourrait provenir d'une induction mécanique de la lipolyse puisque l'importance relative des turbulences, entrées d'air, etc., peut s'accroître pour une installation de traite donnée, lorsque le volume de lait récolté diminue. Toutefois, le niveau de production et le rapport «production de lait/temps de traite» ne semblent expliquer que très partiellement les variations individuelles de lipolyse chez des vaches en milieu ou en fin de lactation (M. P. Chazal et Y. Chilliard, non publié). Dans certaines exploitations, l'augmentation de lipolyse des laits individuels de vaches en fin de lactation peut expliquer entièrement la forte augmentation de la lipolyse du lait de tank mesurée simultanément à la fin de l'été (M. P. Chazal et Y. Chilliard, non publié).

Des modifications du lait natif, liées à la physiologie de l'animal, ne sont pas à exclure. Murphy et al. (1979) rapportent par exemple que les laits du soir ont une activité lipasique plus élevée, et observent que la lipolyse, exprimée par litre de lait, est corrélée au taux butyreux et à la surface de globules gras présente (substrat disponible). La réduction de l'intervalle entre la traite du matin et du soir pourrait donc contribuer à faire augmenter la lipolyse journalière (Judge et al., 1977), dans la mesure où la hausse du soir n'est pas compensée par la baisse du matin (Suhren et al., 1981). Par ailleurs, Moller-Madsen et Horvath (1980) rapportent que les laits de fin de lactation ont une activité lipa- 
sique accrue mais ne semblent pas être plus susceptibles à l'induction de lipolyse que pendant la première partie de la lactation, alors que d'autres auteurs ont observé l'inverse (Speer et al., 1958; Bachmann, 1961).

Une susceptibilité accrue des globules gras à la lipolyse en fin de lactation pourrait être due au fait que le taux butyreux augmente alors que la taille des globules gras diminue, si bien que la surface d'attaque disponible augmente fortement, sans que la teneur en phospholipides du lait n'augmente proportionnellement (Kinsella et Houghton, 1975). En outre la lipase liée à la crème peut aussi augmenter (Tarassuk et Frankel, 1957).

L'cestrus, les maladies ovariennes et les cestrogènes entraînent une augmentation de la lipolyse, probablement due à un accroissement de la quantité de lipase liée à la crème dans le lait natif (Bachman, 1982) et peut-être à la sécrétion d'une lipase anormale très agressive, stimulable par les sels biliaires (Bachmann, 1982, 1984; Heo et al., 1983). Il est possible qu'un effet du stade de gestation se confonde avec celui du stade de lactation, chez la vache.

La lipolyse semble être plus élevée chez les vaches primipares que chez les multipares (Connoly, 1978 ; M. P. Chazal et Y. Chilliard, non publié). Toutefois, la lipolyse augmente chez les vaches multipares âgées (à partir de la septième lactation dans l'étude de Kielsznia et Krolikowska, 1982), peut-être en raison de la baisse du niveau de production et d'une détérioration de l'état sanitaire de la mamelle.

\section{$4^{\circ}$ Alimentation \\ - Niveau alimentaire}

La sous-alimentation augmente parfois la lipolyse «spontanée», surtout lorsqu'elle s'accompagne d'une diminution du niveau de production laitière, en fin de lactation ou chez des vaches faibles productrices. Les résultats de Gholson et al. (1966) montrent que la sous-alimentation peut augmenter la lipolyse après induction par agitation mécanique du lait, mais pas la lipolyse «spontanée ». Il serait donc intéressant de préciser l'effet de ce facteur sur l'état des globules gras ou d'autres composants du système lipolytique.

- Composition de la ration

Il est généralement admis que les rations à base d'herbe favorisent une faible lipolyse mais ceci n'est pas toujours le cas. Un éventuel effet défavorable des fourrages conservés pourrait parfois être dû à leur mauvaise qualité, qui entraînerait une sous-alimentation et des chutes de production. Des régimes fortement déficitaires en azote pourraient entrâ̂ner des augmentations importantes et des teneurs en AGL initiaux (Salih et Anderson, 1979). Les variations observées sur les AGL initiaux suggèrent que cet effet puisse être lié à la physiologie de l'animal.

Des suppléments d'acide palmitique augmentent la lipolyse spontanée, alors que des huiles végétales protégées diminuent la lipolyse 
spontanée (Astrup, 1981) et induite (Urquhart et al., 1984). Il est tentant de rapprocher ces résultats du fait que l'herbe est un aliment riche en acides gras insaturés dont une partie échappe aux fermentations ruminales.

\section{- Transitions alimentaires - Effets saisonniers}

Selon Connolly (1978), la lipolyse pourrait augmenter en cas de stress alimentaire (changement de régime, réalimentation, ...). La lipolyse du lait et des beurres présente généralement un minimum au printemps et un maximum en automne ou en hiver (Kuzdzal-Savoie, 1982b). Des observations récentes suggèrent toutefois que de très fortes lipolyses puissent apparaître dès la période estivale dans certaines régions. Ces variations peuvent résulter de différents effets tels que le stade de lactation ou de reproduction, l'alimentation (ou son effet sur le niveau de production), etc. Les perturbations climatiques (pluie, froid, sécheresse) pourraient jouer au pâturage en diminuant les niveaux de consommation et de production.

\section{$5^{\circ}$ Etat sanitaire}

Le lait contient des cellules somatiques, constituées en majeure partie de leucocytes d'origines sanguine et lymphatique. Le nombre de ces cellules par millilitre de lait varie avec l'état physiologique de l'animal (stade de lactation, ...) et les techniques de traite. Il s'élève fortement dans les cas de mammites cliniques, et il est utilisé pour détecter les mammites subcliniques (Serieys, 1982).

La lipolyse tend à augmenter avec le nombre de cellules somatiques, en particulier au delà de 300000 cellules/ml et dans les laits mammiteux. Les corrélations ne sont toutefois pas toujours élevées. Ceci provient du fait qu'en cas de mammites les transformations du lait sont très complexes et peuvent soit diminuer, soit augmenter la lipolyse (Chilliard, 1982).

Facteurs qui augmentent la lipolyse : les membranes des globules gras sont attaquées par des protéases et phospholipases leucocytaires; la lipase tend à migrer vers la crème, peut-être en raison d'une protéolyse des caséines; le $\mathrm{pH}$ du lait augmente; les lipases leucocytaires augmentent ; des protéines d'origine sanguine passent dans le lait; la production laitière diminue.

Facteurs qui diminuent la lipolyse : la lipase naturelle et ses activateurs peuvent être dégradés par les protéases leucocytaires (Jurczak et Sciubisz, 1982); l'augmentation des teneurs en sels minéraux peut inhiber la lipase ; l'activité lipogénique du lait (estérification des AGL) peut augmenter.

Globalement, il semble que la tendance à augmenter la lipolyse l'emporte faiblement et de façon variable (Anderson et Needs, 1983). En outre, il existe de fortes augmentations des AGL initiaux qui s'ajoutent à la lipolyse pour augmenter la teneur en AGL totaux. Il est à souligner que les mammites sont un des rares facteurs qui entraînent une augmentation sensible des AGL initiaux, probablement du fait d'un 
passage d'AGL sanguins à longue chaîne vers le lait (Needs et Anderson, 1984).

\section{B. Facteurs liés au matériel de traite}

De nombreuses études ont été effectuées depuis les années 50. Elles ont été récapitulées par Fleming (1979). Les entrées d'air dans le circuit du lait (moussages) sont le principal facteur augmentant la lipolyse du lait chaud puis au cours du stockage ultérieur au froid. Pour un niveau donné d'entrée d'air, tout facteur qui augmente les chocs mécaniques (turbulences) ou les variations de pression (vitesses variables) accroît encore la lipolyse, d'autant plus que le lait chaud et riche en matières grasses est très sensible aux inductions de lipolyse ( $(\mathrm{V} \mathrm{B} 1$ ).

Les traites effectuées en pots trayeurs induisent peu (Kankare et Antila, 1978) ou très peu (M. P. Chazal, Y. Chilliard, non publié) de lipolyse par rapport à la traite manuelle.

L'influence des lactoducs est d'autant plus néfaste qu'ils sont longs, avec des coudes, en ligne haute, avec des contre-pentes, des élévateurs ou des goulots d'étranglement. Toutefois ces différents facteurs ont un effet modéré en absence d'entrées d'air alors que cet effet devient très important en cas d'entrées d'air. Ceci a été confirmé sur le lait de chèvre (Morand-Fehr et al., 1984).

Les récipients de contrôle en salle de traite peuvent induire de fortes lipolyses, par le fait que le lait subit des passages forcés dans des coudes, et en raison de l'agitation par entrée d'air qui est utilisée avant la prise d'échantillons (Pillay et al., 1980). Parmi les différents types de compteurs-échantillonneurs qui effectuent un prélèvement proportionnel au flux de lait, certains n'induisent que peu de lipolyse alors que d'autres induisent de fortes lipolyses (M. P. Chazal et Y. Chilliard, non publié). Dans ce dernier cas, le niveau moyen de lipolyse provenant des échantillons individuels peut être beaucoup plus élevé que le niveau « réel » dans le tank à lait.

Les machines à traire du type Zero-Concorde avec des circuits d'air et de laits indépendants, à deux niveaux de vide, induisent nettement moins de lipolyse que les autres (Doody et al., 1975). Ceci a été confirmé depuis par d'autres études aux Pays-Bas, en Angleterre, en Belgique, en Norvège et au Danemark.

Les griffes et le tube à lait sont deux composants pouvant induire de la lipolyse. Parmi les causes importantes d'entrées d'air figurent les manchons trayeurs usagés, les techniques d'égouttage et les glissements de manchons trayeurs (qui peuvent entrainer des entrées d'air allant jusqu'à $200 \mathrm{l} / \mathrm{mn}$ ). Ces facteurs induisent aussi des mammites et peuvent contribuer à la corrélation existant entre mammites et lipolyse. Une lipolyse importante se produit au moment de la pose des manchons trayeurs (M. P. Chazal et Y. Chilliard, non publié) mais elle ne concerne qu'une petite fraction du lait produit. Le manque d'étanchéité des joints des lactoducs est un autre facteur à contrôler. 
Les pompes à lait (centrifuges ou à diaphragme) n'induisent pas de lipolyse lorsqu'elles fonctionnent normalement, sauf éventuellement en fin de lactation. Les problèmes le plus souvent rencontrés le sont avec les pompes centrifuges qui fonctionnent en continu et se retrouvent de ce fait «sous-alimentées ». L'utilisation de pompes à deux vitesses pourrait être intéressante.

En résumé, le point crucial réside dans les entrées d'air, surtout lorsque la conception d'ensemble favorise la formation de mousse, la dégradation des globules gras et la lipolyse (lignes hautes, élévateurs, ...). Le réglage et l'entretien $d u$ matériel sont donc fondamentaux. Les vitesses de transfert élevées et les sous-alimentations de la pompe sont en outre défavorables (cas des faibles niveaux de production).

L'influence d'une partie de ces facteurs a été confirmée dans les conditions françaises, à l'occasion d'une étude conduite récemment par le GIE Lait-Viande de Bretagne (Fremeaux, 1983). $23 \%$ des 9000 échantillons de lait (27\% des élevages) contrôlés avaient des teneurs en AGL supérieures à $0,89 \mathrm{mEq} / 100 \mathrm{~g}$ MG. Les principaux facteurs favorisant la lipolyse étaient l'utilisation des lactoducs, surtout en ligne haute et lorsqu'ils sont longs et associés avec la traite en place dans l'étable; les remontées et les contrepentes; le moussage du lait, la hauteur de chute du lait dans le tank, les chutes directes (non tangentielles), le nombre de coudes, les prises d'air, la sous-alimentation des pompes. Des différences importantes selon les types de machines à traire ont aussi été observées. Par contre des niveaux faibles de lipolyse sont observés dans le cas où la traite s'effectue en pots trayeurs ou en salle de traite, lorsque les installations de traite sont bien réglées et entretenues et la traite effectuée dans des conditions hygiéniques.

Naturellement l'influence des facteurs «hygiène» et « réglage machine » est d'autant plus grande qu'elle concerne à la fois la lipolyse du lait frais et les mammites, mais aussi la lipolyse microbienne à long terme qui n'est généralement pas prise en considération dans les études portant sur le lait frais. Il faut enfin éviter à tout prix la présence de lait résiduel dans les circuits de transfert. En effet, ces laits sont alors contaminés par des bactéries en phase stationnaire de croissance, correspondant à de fortes productions de lipases et protéases. Un demi-litre de lait résiduel peut endommager 10001 de lait frais de bonne qualité.

\section{Facteurs liés au stockage, à la collecte et à la transformation}

En dehors de l'effet propre du refroidissement (cf. § VB), les tanks à lait n'induisent normalement pas de lipolyse supplémentaire sauf en cas d'agitation excessive, et lorsque le volume de lait est insuffisant (pales non recouvertes). Une lipolyse modérée se produit généralement entre la première et la deuxième traite (Miller, 1982) et dans le cas d'une agitation lente en continu (Hoyle et Anderson, 1982) qui lève probablement l'inhibition locale de la lipase par les AGL ou déstabilise les globules gras en cours de cristallisation. Par ailleurs, une température 
trop basse de conservation peut favoriser indirectement la lipolyse, du fait qu'elle requiert plus d'agitation et des risques de congélation. Toutefois le danger le plus fréquent réside dans une insuffisance de refroidissement à chaque traite ou entre les traites, qui favoriserait la lipolyse induite (refroidissement lent et réchauffement du lait des traites antérieures, cf. § V B) et les développements bactériens. L'utilisation de refroidisseurs à plaques pourrait améliorer les choses à condition de ne pas augmenter les contaminations microbiennes.

En fait, c'est surtout la durée de stockage au froid et le nombre de 《manipulations» du lait cru qui sont par eux-mêmes des facteurs de lipolyse naturelle et microbienne (risques accrus dans le cas d'un ramassage 6 traites). La thermisation en sortie de machine à traire pourrait par contre assouplir les contraintes de stockage et de collecte (J.-L. Maubois, Communication personnelle).

Durant la collecte puis la transformation du lait plusieurs facteurs peuvent accroître encore la susceptibilité du lait à la lipolyse ou la lipolyse elle-même : brassages, pompages et vitesses de transfert excessifs; élévations de température; propreté insuffisante du matériel ; agitation dans les citernes insuffisamment pleines durant le transport; turbulences locales (rétrécissements, coudes, remontées); injections d'air au niveau de raccords de tuyauterie lorsque se produisent des dépressions dans le circuit (variations de vitesse et/ou de diamètre) ; délai avant pasteurisation ou thermisation, ... (Fleming, 1979; Lehman, 1981; Wszolek et Kisza, 1982). Il a aussi été montré que le choix des régulateurs de pression peut limiter fortement la lipolyse du lait thermisé (LPL partiellement détruite) soumis à une concentration par osmose inverse (Barbano et al., 1983).

\section{LIPASES DU LAIT ET QUALITE DES PRODUITS LAITIERS}

La lipolyse est un phénomène qui participe positivement à l'élaboration des qualités gustatives de nombreux produits, en particulier des fromages. Mais chaque produit nécessite ou supporte un certain taux de lipolyse, non toujours bien défini, au-delà duquel des goûts de rance ou de savon sont perçus. A cet égard, les actions de la lipase naturelle ou des lipases microbiennes n'ont pas exactement la même signification pratique.

Dans le cas du lait de consommation et des produits frais (yaourt...), la lipolyse naturelle est très dangereuse car elle peut être très rapide si les globules gras sont détériorés, en raison des grandes quantités de lipase qui existent généralement dans le lait frais, et parce que tous les AGL produits restent dans le lait, même après pasteurisation et destruction de la lipase. L'action des lipases microbiennes est négligeable dans les laits pasteurisés de consommation dont le temps de conservation est court, mais elles peuvent intervenir dans les laits de longue conservation, puisque certaines d'entre elles résistent au traitement UHT (Cogan, 1980). Toutefois, dans ces laits, la protéolyse semble être le défaut prédominant. 
Dans le cas des produits dérivés du lait (crème, beurre, fromage), la lipolyse naturelle a des effets en partie limités pour deux raisons : $1^{\circ}$ la lipase naturelle est en grande partie détruite par la pasteurisation ou s'inactive en quelques jours à température ambiante, à $\mathrm{pH}$ acide et en présence de sel dans les produits $(7) ; 2^{\circ}$ les AGL à chaîne courte apparus avant pasteurisation sont en partie solubles dans la phase aqueuse (lactosérum) et éliminés en cours de fabrication (écrémage, barattage, lavage, égouttage). Elle ne doit toutefois pas être négligée, car tous les AGL ne sont pas éliminés (8) et tous les acides gras libres, y compris les acides gras longs, contribuent aux défauts organoleptiques (Woo et Lindsay, 1983).

Par ailleurs, la pasteurisation détruit les germes psychrotrophes mais pas toutes les lipases qu'ils ont sécrétées auparavant, et qui restent en partie associées à la phase grasse. Ces lipases, même en faible quantité, pourront donc agir pendant toute la période de conservation, et sont d'autant plus dangereuses qu'il y a souvent libération préférentielle d'acides gras à courte chaîne, ce qui abaisse le seuil de lipolyse globale tolérable d'un point de vue organoleptique, dans les beurres en particulier (Deeth et al., 1979) (9). Ainsi, $80 \%$ de l'activité lipasique microbienne résiduelle peuvent se trouver concentrés dans la crème et provoquer des défauts lipolytiques. Les développements bactériens dans les beurres sont favorisés par une mauvaise répartition de la phase aqueuse. Des traces de lipases dans les beurres peuvent conduire à des défauts croissants au cours du stockage, même au cours d'une conservation à très basse température et surtout en cas de congélations-décongélations répétées (Woo et Lindsay, 1984).

Les lipases microbiennes peuvent aussi agir dans les poudres de lait, le lait condensé et le lait stérilisé. Enfin, dans les fromages, où les enzymes peuvent s'accumuler 10 fois par rapport au lait initial (Driessen, 1983), une lipolyse exagérée peut être due à la fraction thermostable de lipases microbiennes, notamment dans les fromages à pâte ferme et à maturation lente, mais aussi parfois dans les pâtes molles. En outre, il est possible que les AGL du lait puissent inhiber partiellement certains ferments lactiques utilisés en fabrication (Deeth et Fitz-Gerald, 1976).

(7) Mais les risques d'oxydation dominent dans les beurres salés provenant de crèmes acides (Downey, 1980). Les conditions qui favorisent l'oxydation (acidité, oxygène, sel, ultra-violets, métaux lourds) sont en effet antagoniques avec la lipolyse.

(8) Par exemple, au cours de l'écrémage centrifuge, Anderson et al. (1984) montrent que l'augmentation des AGL dans la crème peut être réduite si la séparation est réalisée à $50^{\circ} \mathrm{C}$ au lieu de 40 . Cette diminution étant liée au moins en partie à l'inactivation partielle de la LPL du lait cru.

(9) Les taux d'AGL n'ont donc qu'une signification très relative sur le plan organoleptique, variable avec la méthode de dosage, la nature des phénomènes de lipolyse, la nature des AGL produits et les conditions physicochimiques du lait ou des produits laitiers. 
Les niveaux de lipolyse nécessaires à l'optimisation des qualités gustatives varient avec la nature des produits et les habitudes alimentaires ou les caractéristiques physiologiques des populations qui les consomment. Il est bien connu que l'utilisation de crèmes ou de beurres rances est parfois recherchée en chocolaterie et en pâtisserie. L'addition dans les fabrications de certains fromages italiens d'enzymes lipolytiques vendues dans le commerce qui libèrent des acides gras à courte chaîne est un autre aspect des mesures prises pour maitriser et atteindre un niveau de lipolyse optimum.

Les risques de lipolyse excessive dus aux enzymes thermostables sont très difficiles à estimer. Ils le sont souvent par rapport à la charge en bactéries psychrotrophes du lait initial, dans la mesure où il n'existe pas de données reliant les constatations de défauts aux niveaux d'activités enzymatiques. Toutefois, l'étude de Mottar (1981) sur 25 laits de 5 usines belges montre que la numération des germes psychrotrophes n'est pas corrélée avec les activités enzymatiques résiduelles dans les laits UHT, l'effet souche semblant plus important que le nombre.

Cogan (1977) pense par ailleurs que des risques peuvent exister avec très peu de micro-organismes $\left(10^{3} / \mathrm{ml}\right)$ s'ils produisent de grandes quantités d'enzymes thermostables. Cependant, on considère généralement que des taux inférieurs à 250000 germes totaux à l'arrivée à la laiterie ne posent pas de problèmes de lipolyse (Schipper, 1975). A la suite de la majorité des auteurs, Muir et Phillips (1984) ont estimé que, dans le lait cru, la fréquence de perception des défauts organoleptiques est de 3-4\% quand le nombre de bactéries est situé entre $10^{6}$ et $5 \times 10^{6} / \mathrm{ml}$. Elle atteint $25-30 \%$ lorsque les dénombrements sont supérieurs à $5 \times 10^{6}$ avec un seuil entre $10^{6}$ et $10^{7}$ pour les crèmes et les beurres, et entre 2 et $8 \times 10^{6}$ pour les fromages. Ils montrent qu'il est théoriquement possible de calculer une probabilité de stockage en "sécurité » du lait dans les usines pour différentes durées et températures, avant pasteurisation, en fonction de la contamination initiale et pour diverses valeurs du temps apparent de génération de la flore psychrotrophe. Toutefois ces auteurs confirment que la thermisation précoce reste l'alternative la plus souple et qui a le plus de chance de succès contre la multiplication de la flore psychrotrophe, tout en réduisant l'activité de la lipase naturelle.

Une mesure rapide, spécifique et sensible des taux de lipases microbiennes après pasteurisation serait des plus utiles à mettre au point.

\section{CONCLUSION}

La mécanisation, l'automatisation et la rationalisation des techniques de production, de récolte, de stockage, de collecte, de transformation et de distribution du lait et des produits laitiers ne s'accompagnent pas inéluctablement d'un accroissement important du taux de lipolyse. Les 


\section{TABLEAU 2}

Principales mesures envisageables pour prévenir la lipolyse dans le lait Recommendations for the prevention and the control of milk lipolysis

\section{Facteur animal}

- Réformer les vaches dont le lait lipolyse régulièrement, en particulier les vaches âgées, atteintes de mammites, de maladies ovariennes et qui donnent lentement leur lait ou ont des mamelles mal conformées.

- Prophylaxie des mammites.

- Etalement des mises-bas ; passage à une seule traite par jour puis tarissement précoce en fin de lactation $(<5-10 \mathrm{~kg} /$ jour $)$.

- Alimenter selon les besoins, avec des aliments de bonne qualité, éviter les suppléments riches en acide palmitique.

- Eviter les stress (changements brutaux de régime ; conditions de vie...).

- Ne pas trop réduire l'intervalle traite du matin - traite du soir.

Lipolyse induite

- Réduire si possible la traite en place, les lactoducs ligne haute, les transferts sur de longues distances, avec des coudes, des joints, des robinets, des contrepentes, des goulots d'étranglement, des filtres dans le circuit du lait sous vide.

- Eliminer les manchons trayeurs usagés, éviter les glissements en cours de traite, la surtraite et l'égouttage excessif.

- Bien régler le matériel, en particulier l'entrée d'air à la griffe et bannir toute entrée d'air inutile dans les circuits.

- Utiliser des machines à traire à deux circuits, surtout avec les installations en ligne haute.

- Eviter l'utilisation systématique des récipients de contrôle mal conçus.

- Eviter la sous-alimentation des pompes et les vitesses de transfert excessives.

- Eviter les chutes directes (non tangentielles) et en réduire la hauteur.

- Thermisation en sortie de machine à traire.

- Refroidissement rapide du lait dans le tank; éviter les fluctuations de température à chaque traite et entre les traites; ne pas refroidir en dessous de $0^{\circ} \mathrm{C}$.

- Ne pas agiter trop fortement et trop longtemps, et surtout à la première traite et si le tank est trop grand (pales non immergées).

- Ramasser le lait avant la traite du matin, de façon à ce que le lait du matin (moins susceptible) soit le lait de première traite dans le tank.

- Eviter les ramassages "six traites ", les citernes de ramassage trop grandes et mal réfrigérées ; les ramassages à grande distance...

- Pasteurisation précoce et suffisante $\left(78^{\circ} \mathrm{C}, 10 \mathrm{sec}\right.$. au moins) avant homogénéisation. Ecrémage à chaud.

- Ne pas mélanger de lait homogénéisé avec du lait cru.

\section{Lipolyse microbienne}

- Hygiène et nettoyage stricts à la traite ; du matériel de traite, de stockage, de collecte ; éviter tout lait résiduel dans les circuits.

- Refroidissement rapide et conservation du lait à $2-3^{\circ} \mathrm{C}$ dans le tank.

- Pasteurisation ou thermisation $\left(65^{\circ} \mathrm{C}-15 \mathrm{sec}\right.$.) précoce.

- Conservation moins longue et à basse température des produits.

\section{Mesures générales}

- Contrôles de lipolyse à la collecte et aide technique.

- Conseils pour la conception, le réglage et l'entretien des installations. 
exemples précédents montrent qu'il est possible de prendre des mesures pratiques efficaces à cet égard (tableau 2) et l'action entreprise par le GIE Bretagne va dans ce sens (appui technique à différents niveaux).

L'étude des mécanismes des différents types de lipolyse (figure 4) doit être poursuivie afin de participer à la progression des connaissances et de faciliter la maîtrise des problèmes pratiques. Le facteur animal et l'influence des techniques d'élevage sont peut-être négligés car ils sont complexes et très mal connus, et ils doivent de plus être étudiés en interaction avec tous les autres facteurs induisant de la lipolyse (et pas seulement au début de la filière).

En fait, le problème de la lipolyse s'inscrit dans un «syndrome» général de mauvaise qualité du lait et il est lié soit dans ses causes, soit dans ses conséquences aux problèmes de qualité bactériologique (psychrotrophes, butyriques, thermorésistants, ...), de protéolyse, d'oxydation, de structure de la matière grasse (baisse du rendement à l'écrémage, dureté...) et de mammites.

\section{Remerciements}

Nous remercions P. Cartier et M.P. Chazal (ITEB) pour leur participation à la relecture et à la discussion de ce texte.

\section{Bibliographie}

AdAMS (D.M.), BRAWley (T.G.) (1981). - Heat resistant bacterial lipases and ultra-high temperature sterilization of dairy products. J. Dairy Sci., 64, 1951-1957.

Amariglio (S.) (1984). - Communication au Comité d'Action Lipolyse de l'Association Laitière Française (19 juin 1984).

ANDERSON (M.) (1981). - Inhibition of lipolysis in bovine milk by proteose peptone. I. Dairy Res., 48, 247-252.

ANDERSON (M.) (1982). - The relationship between fat damage, substrate availability and lipolysis in milk and cream. ICODRL-Meeting on " Effect of fat damage in raw milk on the quality and yield of products » in Zürich, Switzerland, on October 21-22.

ANDERSon (M.) (1983). - Milk lipase and off-flavour development. J. Soc. Dairy Technol., 36, 3-7.

ANDERSON (M.), NEEDS (E.C.) (1983). - Serum lipoprotein stimulation of lipolysis and its relevance to free fatty acid development in bovine milk. J. Dairy Res., 50, 309-319.

ANderson (M.), NeEds (E.C.), Price (J.C.) (1984). - Lipolysis during the production of double cream, J. Soc. Dairy Technot., 37, 19-22.

Anderson (R.E.), Heolund (C.B.), Jonsson (U.) (1979). - Thermal inactivation of a heat-resistant lipase produced by the psychrotrophic bacterium Pseudomonas fluorescens. J. Dairy Sci., 62, 361-367.

Astrup (H.N.) (1981). - The feed and lipolysis in milk. Contribution at a LIPIDFORUM seminar-Göteborg, March 9-10, p. 81-83.

AzZARA (C.D.), Dimick (P.S.) (1984). - Leukocytes : A source of lipolytic enzyme activity in normal and subclinically mastitic bovine milk. J. Dairy Sci., 67, Suppl. 1, 241. 
BACHMAN (K.C.) (1982). - Effect of exogenous estradiol and progesterone upon lipase activity and spontaneous lipolysis in bovine milk. J. Dairy Sci., 65, 907-914.

BACHMANN (E.W.) (1982). - Lipolysis without prior damage of the fat globule membrane. ICODRL-Meeting on "Effect of fat damage in raw milk on the quality and yield of products ", in Zürich, Switzerland, on October 21-22.

Bachmann (M.) (1961). - Das Problem der Ranzigkeit in Milch und Käse. Schweiz. Milchzeitung, 87, Nr. 53, 1-19, Wissenschaftl. Beilage Nr. 79.

BACHMANN (M.R.) (1984). - Que savons-nous aujourd'hui du lait rance et du fromage rance ? Le Laitier romand et Journal suisse du lait, 29, 1-2 et $31,1-2$.

Barbano (D.M.), Bynum (D.G.), Senyk (G.F.) (1983). - Influence of reverse osmosis on milk lipolysis. J. Dairy Sci., 66, 2447-2451.

Bauchart (D.), CHIlliard (Y.) (1983). - Analyse quantitative et qualitative des acides gras libres au cours de la lipolyse du lait de vache, par adsorption sur résine échangeuse d'ions et par chromatographie en phase gazeuse. 9 p., brochure ITEB-INRA, $\mathrm{n}^{\circ} 84031$.

Bengtsson (G.), Olivecrona (T.) (1982). - Activation of lipoprotein lipase by apoliprotrotein CII. Demonstration of an effect of the activator on the binding of the enzyme to milk-fat globules. FEBS Lett., 147, 183-187.

Bengtsson (G.), Olivecrona (T.) (1983). - The effects of $\mathrm{pH}$ and salt on the lipid binding and enzyme activity of lipoprotein lipase. Biochim. Biophys., Acta, 751, 254-259.

Bhavadasan (M.K.), Abraham (M.J.), Ganguli (N.C.) (1982). - Influence of agitation on milk lipolysis and release of membrane-bound xanthine oxidase. J. Dairy Sci., 65, 1692-1695.

Castberg (H.B.), Egelrud (T.), Solberg (P.), Olivecrona (T.) (1975), - Lipases in bovine milk and the relationship between the lipoprotein lipase and tributyrate hydrolysing activities in cream and skim-milk. J. Dairy Res., 42, 255-266.

ChIlliaRd (Y.) (1982). - Variations physiologiques des activités lipasiques et de la lipolyse spontanée dans les laits de vache, de chèvre et de femme : Revue bibliographique. Le Lait, 62, 1-31 et 126-154.

Chilliard (Y.), Bauchart (D.), Cartier (P.) (1983). - Comparaison de cinq méthodes titrimétriques avec une méthode chromatographique de dosage des acides gras libres du lait de vache. 15 p., brochure ITEB-INRA, n 84031.

CHILliard (Y.), DoREaU (M.) (1985). - Characterization of lipase in mare milk. J. Dairy Sci., 68, 37-39.

Chilliard (Y.), Sauvant (D.) (1984). - Origine et biosynthèse des lipides et des protéines du lait. $36 \mathrm{p}$. In * La composition chimique du lait et ses incidences technologiques ». Colloque INRA-ENSAR-INAPG, Rennes, sept. 1984.

Chilliard (Y.), Selselet-Attou (G.), Bas (P.), Morand-Fehr (P.) (1981). - Facteurs influençant la lipolyse du lait de chèvre. $6^{\text {es }}$ Journées de la recherche ovine et caprine (Toulouse), p. 332-350.

Chmliard (Y.), Selselet-Attou (G.), Bas (P.), Morand -Fehr (P.) (1984). - Characteristics of lipolytic system in goat milk. J. Dairy Sci., 67, 2216-2223.

Chorsy (C.), Lenoir (J.) (1984). - La réfrigération du lait et ses incidences sur la qualité bactériologique. $8 \mathrm{p}$. In « $\mathrm{La}$ composition chimique du lait et ses incidences technologiques ». Colloque INRA-ENSAR-INAPG, Rennes, sept. 1984.

Chrisope (G.L.), MARshall (R.T.) (1976). - Combined action of lipase and microbial phospholipase $\mathrm{C}$ on a model fat globule emulsion and raw milk. J. Dairy Sci., 59, 2024-2030.

CLEGG (R.A.) (1980). - Activation of milk lipase by serum proteins : possible role in the occurrence of lipolysis in raw bovine milk. J. Dairy Res., 47, 61-70.

COGAN (T.M) (1977). - A review of heat resistant lipases and proteinases and the quality of dairy products. Ir. J. Fd. Sci. Technol., 1, 95-105. 
Cogan (T.M.) (1980). - Lipases et protéinases thermorésistantes et qualité des produits laitiers. Bull. Féd. Int. Laiterie, doc. 118, 28-35.

Connolly (J.F.) (1978). - Recent findings on lipolysis in Ireland. The impact of environment and nutrition on free fatty acids and flavour in milk and dairy products. 20 th. Int. Dairy Congress, doc. 62 ST (B), 32 p.

Cousin (M.A.) (1982). - Presence and activity of psychrotrophic microorganisms in milk and dairy products : a review. $J$. Food Protect., 45, 172-207.

DEETH (H.C.) (1982). - Phospholipases produced by Pseudomonas fluorescens isolated from raw milk. 21e Congrès Int. Laiterie, vol. 1, livre 2, 297.

DeETh (H.C.), Fitz-Gerald (C.H.) (1976). - Lipolysis in dairy products : a review. Austr. J. Dairy Technol., 31, 53-64.

DeETH (H.C.), Fitz-Gerald (C.H.) (1977). - Some factors involved in milk lipase activation by agitation. J. Dairy Res., 44, 569-583.

DeETH (H.C.), Fitz-Gerald (C.H.) (1978). - Effects of mechanical agitation of raw milk on the milk-fat globule in relation to the level of induced lipolysis. J. Dairy Res., 45, 373-380.

DeEth (H.C.), Fitz-Gerald (C.H.), Wood (A.F.) (1979). - Lipolysis and butter quality. Austr. J. Dairy Technol., 34, 146-149.

Deeth (H.C.), Madsen (O.) (1978). - La détection fluorimétrique de l'activité de la carboxyl-estérase dans le lait. $20^{\circ}$ Congrès Int. Laiterie, vol. F., 369-370.

Doody (K.), O'Shea (J.), RAFTERY (T.F.) (1975). - Influence of design of milking equipment on lipolysis. Bull. Féd. Int. Laiterie, doc. 86, 146-155.

DOWNEY (W.K.) (1980). - Review of the progress of dairy science : Flavour impairment from pre- and postmanufacture lipolysis in milk and dairy products. $J$.Dairy Res., 47, 237-252.

DRIESSEN (F.M.) (1983). - Lipases and proteinases in milk. Occurrence, heat inactivation, and their importance for the keeping quality of milk products. Thèse V 236, Nederlands Instituut voor Zuivelonderzoch (157 p.).

DRIESSEN (F.M.), STADHOUdERS (J.) (1974). - Thermal activation and inactivation of exocellular lipases of some Gram-negative bacteria common in milk. Neth. Milk Dairy J., 28, 10-22.

FÉDÉRation INTERnationale De LaIterie (1974). - La lipolyse dans le lait refroidi en vrac. Bull. Ann., doc. 82,40 p.

FÉdération Internationale de Latterie (1975). - Proceedings of the lipolysis Symposium (Cork. Ireland) compiled by W.K. Downey and J.M. Cogan. Bull. Ann. doc. 86, 197 p.

FÉdération Internationale de Laiterie (1980). - Anomalies du goût du lait et des produits laitiers dues à la lipolyse. Bull. Ann., doc. 118, $81 \mathrm{p}$.

FÉdÉRATION INTERNATIONALE DE LAITERIE (1982). - Lipolysis. Results of questionnaire $282 / \mathrm{A}, 50 \mathrm{p}$.

Fitz-Gerald (C.H.), DeEth (H.C.) (1983). - Factors influencing lipolysis by skim milk cultures of some psychrotrophic microorganisms. Austr. J. Dairy Technol., 38, 97-103.

FITZ-GERALD (C.H.), DEETH (H.C.), Coghill (D.M.) (1982). - Low temperature inactivation of lipases from psychrotrophic bacteria. Austr. I. Dairy Technol., 36, 51-54.

FLEMING (M.G.) (1979). - Lipolysis in bovine milk as affected by mechanical and temperature activation : a review. Ir. J. Fd. Sci. Technol., 3, 111-129.

Fox (C.W.), CHRISOPE (G.L.), MARShall (R.T.) (1976). - Incidence and identification of phospholipase C-producing bacteria in fresh and spoiled homogenized milk. J. Dairy Sci., 59, 1854-1857.

Fox (P.F.), STEPANIAK (L.) (1983). - Isolation and some properties of extracellular heat stable lipases from Pseudomonas fluorescens strain AFT 36. J. Dairy Res., 50, 77-89.

Fremeaux (P.) (1983). - Lipolyse : le G.I.E. lait-viande mène l'enquête. Production Laitière Moderne, 120, 82-86.

GHolson (J.M.), SchexNAILder (R.H.), RusOFF (L.L.) (1966). - Influence of a poor-quality low-energy ration on lipolytic activity in milk. J. Dairy Sci., $49,1136-1139$. 
GRAPPIN (R.), JeUnet (R.) (1981), - Influence of lipolysis on gravimetric and routine methods for milk fat test. J. Dairy Sci., 64, Suppl. 1, 41.

GRIFFITHS (M.W.) (1983). - Synergistic effects of various lipases and phospholipase C on milk fat. J. Fä. Technol., 18, 495-505.

Griffiths (M.W.), Phillips (J.D.), MUIR (D.D.) (1981). - Thermostability of proteases and lipases from a number of species of psychrotrophic bacteria of dairy origin. J. Appl. Bacteriol., 50, 289-303.

Heo (T.R.), Amado (R.), Bachmann (W.R.) (1983). - Beitrag zur Kenntnis des Lipasesystemes der Milch. Schweiz. Milchw. Forschung, 12, 59-65.

Hernell (O.), Olivecrona (T.) (1974). - Human milk lipases, I. Serum-stimulated lipase. J. Lipid Res., 15, 367-374.

HofMANN (C.J.), KeENAN (T.W.), Eigel (W.N.) (1979). - Association of plasminogen with bovine milk fat globule membrane. Int. J. Biochem., 10, 909-917.

Hoyle (J.B.), ANDERSON (M.) (1982). - The effect of modes of agitation in a farm bulk tank on free fatty acid development. $21^{\mathrm{e}}$ Congrès Int. Laiterie, vol. 1, livre $1,105$.

Jellema (A.) (1980). - Physiological factors associated with lipolytic activity in cow's milk. Bull. Féd. Int. Laiterie, doc. 118, 33-40.

Judge (F.J.), Fleming (M.G.), O'Shea (J.), RAFTeRY (T.F.) (1977). - Effect of milking pipeline height and excessive air admission at the claw on free fatty acid development in raw milk. Ir. J. agric, Res., 16, 115-122.

JuRCZAK (M.E.), ScIUBisz (A.) (1982). - Influence of $\alpha$-lipoprotein and degradation of somatic cells in milk on the spontaneous lipolysis. $21^{\text {e }}$ Congrès Int. Laiterie, vol, 1, livre 2, 197.

KANKARE (V.), ANTILA (V.) (1978). - Influence of pipeline milking machines on lipolysis in farm milk. 20th Int. Dairy Congress, vol. E., 132.

Kester (J.J.), BRunNeR (J.R.) (1982). - Milk fat-globule membrane as possible origin of proteose-peptone glycoproteins. J. Dairy Sci., 65, 2241-2252.

KTELSZnia (R.), KRoliKowSKa (E.) (1982). - Influence of various factors upon the lipolytic changes in cow's milk. $21^{\circ}$ Congrès Int. Laiterie, vol. 1, livre 2, 145.

Kinsella (J.E.), Houghton (G.) (1975). - Phospholipids and fat secretion by cows on normal and low fiber diets : lactational trends, J. Dairy Sci., 58, 1288-1293.

Kirst (E.), WestPhaL (G.) (1983). - Zur Lipolyse der Milch durch technologische Beeinflussungen. 2. Mitt. Untersuchungen zum Einfluss der Milchfettzusammensetzung auf die lipolytischen Veranderungen bei der Kühlıng der Milch. Die Nahrung, 27, 1-8.

KRUKOVSKY (V.N.), HERRINGTON (B.L.) (1939). - Studies of lipase action. II. The activation of milk lipase by temperature changes. J. Dairy Sci., 22, 137-147.

Kuzdzal-Savoie (S.) (1982 a). - La lipolyse dans les crèmes et les beurres : acidité libre et appréciation organoleptique. La Technique Laitière, 967, 12-15.

KuzDzal-Savore (S.) (1982 b). - La dégradation lipolytique de la matière grasse laitière. La Technique Laitière, 966, 17-26.

LaNdass (A.), Solberg (P.) (1978). - Production et caractérisation d'une lipase d'un Pseudomonas fluorescens. 20e Congrès Int. Laiterie, vol. F, 311-312.

LAUdRen (G.) (1983), - Améliorer la qualité des laits : un objectif fondamental pour les cinq prochaines années, à réaliser ensemble par les producteurs et les transformateurs. Elevage Rentabilité, 181, 11.

LaW (B.A.) (1979). - Reviews of the progress of dairy science : Enzymes of psychrotrophic bacteria and their effects on milk and milk products. J. Dairy Res., 46, 573-588.

Lehman (H.) (1981). - In Pointurier (H.) (1982) : « Qualité et rendement dans les produits laitiers gras ». Séminaire de l'Association Laitière Allemande, Bonn, 2 déc. 1981, doc. Westfalia Separator France.

Luzeau (R.), Odièvre (M.), Levillain (P.), Lemonnier (A.) (1975). - Activité de la lipoprotéine lipase dans les laits de femme, inhibiteurs in vitro de la conjugaison de la bilirubine. Clin. Chim. Acta, 59, 133-138. 
Mac Pherson (A.V.), Fitz-Gerald (C.H.), Krtchen (B.J.) (1981). - Isolation of a low density lipoprotein complex from butter and its suitability as a substrate for lipases from psychrotrophic microorganisms. Aust. J. Dairy Technol., 36,7478 .

Mac Pherson (A.V.), Kitchen (B.J.) (1983). - Reviews of the progress of dairy science : The bovine milk fat globule membrane. Its formation, composition, structure and behaviour in milk and dairy products. J. Dairy Res., 50, 107-133.

Marin (A.), Marshall (R.T.) (1983). - Production of glycosidases by psychrotrophic bacteria. J. Food Sci., 48, 570-573.

MARin (A.), MaWhinNey (T.P.), MaRshall (R.T.) (1984). - Glycosidic activities of Pseudomonas fluorescens on fat extrated skim milk, buttermilk and milk fat globule membranes. J. Dairy Sci., 67, 52-59.

Marshall (J.) (1983). - Lipolysis : still a problem for the unwary. Austr. J. Dairy Technol., Suppl. December, p. 3.

MaRshall (R.T.) (1982). - Relationship between the bacteriological quality of raw milk and the final products. A review of basic information and practical aspects. Kieler Milchwirtsch. Forschungsber., 34, 149-157.

MATHER (I.H.), KEENAN (T.W.) (1975). - Studies on the structure of milk fat globule membrane. J. Membr. Biol., 21, 65-85.

Miller (B.) (1982), - Extent of fat damage under practical conditions in Switzerland. ICODRL-Meeting on "Effect of fat damage in raw milk on the quality and yield of products $"$ in Zürich, Switzerland, on October 21-22.

MiRANDA (G.), GRIPON (J.C.) (1984). - Origine et nature de la protéolyse dans le lait. $18 \mathrm{p}$. In " La composition chimique du lait et ses incidences technologiques ". Colloque INRA-ENSAR--INAPG, Rennes, sept. 1984.

Moller-Madsen (A.), HoRVATh (Z.) (1980). - The influence of some physiological factors on the lipolytic activity and content of free fatty acids in raw whole milk. Beretning fra Statens Forsogsmejeri, n ${ }^{\circ} 239,30$ p. (Danois).

Morand-Fehr (P.), Selselet-Attou (G.), Bas (P.), Chilliard (Y.) (1984), - Facteurs liés à la traite favorisant la lipolyse induite du lait de chèvre. $3^{e}$ Symp. Int. Traite mécanique petits ruminants, 1983, Valladolid, Espagne, 12 p. (sous presse).

MoRTEnSEN (B.K.), JANSEN (K.) (1982). - Lipase activity in cream and butter. 21 ${ }^{\text {e }}$ Congrès Int. Laiterie, vol. 1, livre 1, 334-335.

MotTAR (J.) (1981). - Heat resistant enzymes in UHT milk and their influence on sensoric changes during uncooled storage. Milchwissenschaft, 36, 87-91.

MUiR (D.D.), Phillips (J.D.) (1984). - Prediction of the shelf life of raw milk during refrigerated storage. Milchwissenschaft, 39, 7-11.

Murphy (J.J.), Connolly (J.F.), Headon (D.R.) (1979). - A study of factors associated with free fatty acid development in milk. Ir. J. Fd. Sci. Technol., 3, 131-149.

NEeDs (E.C.), ANDERson (M.) (1984). - Lipid composition of milks from cows with experimentally induced mastitis. J. Dairy Res., 51, 239-249.

O'DonNell (E.T.) (1978). - Résistance à la chaleur des lipases produites par les bactéries psychrotrophes. $20^{\circ}$ Congrès Int. laiterie, vol. F, 314.

Ourvecrona (T.) (1980). - Biochemical aspects of lipolysis in bovine milk. Bull. Féd. Int. Laiterie, doc. 118, 19-25.

PILlay (V.T.), Myhr (A.N.), Gray (J.I.), Biggs (D.A.) (1980). - Lipolysis in milk. II. Effect of milking systems. J. Dairy Sci., 63, 1219-1223.

Rowe (M.T.), Gullmour (A.) (1983). - Nutritional factors affecting extracellular enzyme production by Pseudomonas fluorescens B 52. Milchwissenschaft, 38, 705-707.

SAlih (A.M.A.), ANDERSon (M.) (1979), - Effect of diet and stage of lactation on bovine milk libolysis. J. Dairy Res., 46, 623-631.

SCHIPPER (C.J.) (1975), - Prevention of bacteriological lipolysis by dairy factories. Bull. Féd. Int. Laitière, doc. 86, 113-115. 
Schwartz (P.) (1974). - The lipids of milk : deterioration. Part 1. Lipolysis and rancidity, p. 220-239. In WeBB (B.H.), JoHNSON (A.H.) and ALFORD (J.A.) : "Fundamentals of Dairy Chemistry ». The AVI Publ. Comp. Inc., Westport, Connecticut (U.S.A.).

SERIEYS (F.) (1982). - Les comptages cellulaires par vache : signification et utilisation des résultats. Production Laitière Moderne, 109, 43-48.

SHIPE (W.F.), SENYK (G.F.) (1981). - Effects of processing conditions on lipolysis in milk. J. Dairy Sci., 64, 2146-2149.

SPEer (J.F. Jr), WATrous (G.H. Jr), KESLER (E.M.) (1958). - The relationship of certain factors affecting hydrolytic rancidity in milk. J. Milk Food. Technol, 21, 33-37.

Suhren (G.), Hamann (J.), Heeschen (W.), Tolle (A.) (1981). - Zum Einfluss tierindividueller Faktoren, des Gemelksfraktion und des Melkzeitintervalls auf den Gehalt freir Fettsäuren (FFA) in Rohmilch. Milchwissenschaft, 36, $150-153$.

SundHeIM (G.), Zimmer (T.L.), Astrup (H.N.) (1983), - Induction of milk lipolysis by lipoprotein components of bovine blood serum. J. Dairy Sci., 66, 400-406.

TARASSuK (N.P.), Frankel (E.N.) (1957). - The specificity of milk lipase. IV. Partition of the lipase system in milk. J. Dairy Sci, , 40, 418-430.

Te Wharti (I.E.), Fryer (T.F.) (1978). - La production des protéases et des lipases de Pseudomonas psychrotrophes dans le lait et leur stabilité à la chaleur. $20^{\circ}$ Congrès Int. laiterie, vol. F, 310-311.

Urouhart (A.), CadDEN (A.M.), Jelen (P.) (1984). - Quality of milk and butter related to canola-based protected lipid feed supplement. Milchwissenschaft, $39,1-6$.

Vainto (P.), Virtanen (J.A.), Kinnunen (P.K.J.) (1982). - Inhibition of lipoprotein lipase by benzene boronic acid. Effect of apolipoprotein C-II. Biochim. Biophys. Acta, 711, 386-390.

WALSTRA (P.) (1978). - The milk fat globule : natural and synthetic. 20th Int. Dairy Congress, doc. $75 \mathrm{ST}, 18 \mathrm{p}$.

WANG (L.), RANDOLPH (H.E.) (1978). - Activation of lipolysis. I. Distribution of lipase activity in temperature activated milk. J. Dairy Sci., 61, 874-880.

WierRe (T.), GRAPPIN (R.) (1979). - Influence de la lipolyse et de la protéolyse sur le dosage des matières grasse et azotée du lait. Mémoire INRA Poligny ENSA Rennes.

Winter (R.), Pabst (K.), OrdolfF (D.), Gravert (H.O.) (1981). - Tierspezifische Lipaseaktivität in der Kuhmilch. Kieler Milchwirtsch. Forschungsber., 33, $221-226$

Woo (A.H.), LINDSAY (R.C.) (1983). - Statistical correlation of quantitative flavor intensity assessments and individual free fatty acid measurements for routine detection and prediction of hydrolytic rancidity off-flavors in butter, J. Food Sci., 48, 1761-1777.

Woo (A.H.), LINDSAY (R.C.) (1984). - Characterization of lipase activity in coldstored butter. J. Dairy Sci., 67, 1194-1198.

Wooding (F.B.P.) (1975). - Ultrastructural aspects of formation and fate of the milk fat globule membrane. Bull. Féd. Int. Laiterie, doc. 86, 7-8.

Wooding (F.B.P.), KEMP (P.) (1975). - High-melting-point triglycerides and the milk-fat globule membrane. J. Dairy Res., 42, 419-426.

WszoleK (M.), Kisza (J.) (1982), - Lipolysis of raw milk fat. $21^{\mathrm{e}}$ Congrès Int. Laiterie, vol. 1, livre 1, 159. 